\title{
Avaliação quantitativa da geomorfodiversidade da Zona Costeira de Icapuí/CE, Brasil
}

\author{
Quantitative evaluation of Sites of Geomorphological Interest of The Coast Zone of Icapuí / \\ CE, Brazil
}

\begin{abstract}
Isa Gabriela Delgado de Araújo
Mestranda em Geografia, Universidade Federal do Rio Grande do Norte, Brasil isiinhad@hotmail.com
\end{abstract}

Matheus Dantas das Chagas Graduando em Licenciatura em Geografia, Universidade Federal do Rio Grande do Norte, Brasil matheuschagas@outlook.com

Marco Túlio Mendonça Diniz Pós-Doutor em Geografia, Universidade Federal do Rio Grande do Norte, Brasil tuliogeografia@gmail.com

\begin{abstract}
Resumo
Com o aumento das preocupações da humanidade com o meio ambiente na segunda metade do século $\mathrm{XX}$, os estudos sobre os elementos abióticos da natureza aumentaram exponencialmente. O presente trabalho tem por objetivo avaliar os sítios de interesse geomorfológico em Icapuí - Ceará, Brasil. Para isto, foi desenvolvido uma ficha de avaliação, embasada em estudos anteriores, em que cada um desses estudos apresentou uma forma de avaliação. Após a elaboração da ficha, foi realizado o trabalho de campo. Foram identificados, no município, sítios com alta valoração cientifica e estético, estes sendo classificados como geomorfossítios e aqueles que não apresentam altos valores estético ou científicos, mas possuem algum outro tipo de valor foram denominados de sítios da geomorfodiversidade. Contabilizou-se, assim, no município de Icapuí, o total de cinco geomorfossítios e três sítios da geomorfodiversidade.
\end{abstract}

Palavras-chave: Elementos abióticos; Geomorfossítios; Icapuí.

\begin{abstract}
With the increase in humanity's concerns for the environment in the second half of the 20th century, studies on the abiotic elements of nature have increased exponentially. This work aims to evaluate the sites of geomorphological interest in Icapuí - Ceará, Brazil. For this, an evaluation form was developed based on previous studies. Each of these studies presented a form of evaluation. After elaboration of the form, fieldwork was carried out. In the municipality, sites with high scientific and aesthetic value were identified. These were classified as geomorphosites and those that do not have high aesthetic or scientific values, but they have some other type of value called geomorphodiversity sites. Thus, in the municipality of Icapuí, a total of five geomorphosites and three geomorphodiversity sites were counted.
\end{abstract}

Keywords: Abiotic elements; Geomorphosites; Icapuí. 


\section{INTRODUÇÃO}

Os estudos acerca da vertente abiótica (geodiversidade) do patrimônio natural se estabeleceram a partir de meados do século XX, com ascensão principalmente, na década de 1990 (GRAY, 2004). Esse fato é resultado das preocupações ambientais motivadas pela utilização dos recursos naturais pela humanidade, de forma acentuada ao longo do tempo. Fruto do uso desmedido de determinadas áreas surge a necessidade de conservação dos elementos abióticos (geoconservação), pois eles não possuem a condição de regeneração na escala de tempo na sociedade.

Gray (2013, p.12) definiu a geodiversidade como

the natural range (diversity) of geological (rocks, minerals, fossils), geomorphological (landforms, topography, physical processes), soil and hydrological features. It includes their assemblages, structures, systems and contributions to landscapes.

Essa Geodiversidade comporta o patrimônio abiótico ou geopatrimônio, a Comissão Brasileira de Sítios Geológicos e Paleobiológicos (SIGEP) apresenta uma gama de Geopatrimônio em várias categorias como o patrimônio geológico, geomorfológico, paleontológico, estratigráfico e outros. O patrimônio geomorfológico para Panizza (2001) é definido pelas formas de relevo, quando valoradas (pelos valores cênico, socioeconômico, cultural e científico) são denominadas como geomorfossítios.

Os geomorfossítios são caracterizados por duas vertentes, assim como transcorre para os geossítios: uma forma restrita e outra ampla. A primeira é referente a um alto valor científico, proposto por Brilha (2016) para o patrimônio geológico e Reynard et al., (2007) para o geomorfológico, e a segunda remete aos outros valores (cênico, cultural, ecológico, turístico e outros), desenvolvida por autores como Panizza e Piacente (1993) e Panizza (2001). Dessa forma, o artigo estende a versão restrita, destacando o valor científico e estético como valores centrais.

Os estudos sobre a geomorfologia na geodiversidade a nível mundial passaram a ter destaque a partir da criação do Grupo de Trabalho (Geomorphosites) pela Associação Internacional de Geomorfologistas (International Association of Geomorphologists - IAG), na V Conferência Internacional de Geomorfologia, realizada em Tóquio, em que foram discutidos conceitos, métodos de avaliação, mapeamentos e proteção (REYNARD, PANIZZA 2005, REYNARD, CORATZA 2007).

No Brasil, de acordo com Claudino-Sales (2018), a União da Geomorfologia Brasileira (UGB) só foi convidada a colaborar e integrar a SIGEP (Comissão Brasileira de Sítios Geológicos e Paleobiológicos), órgão que verifica sítios significativos no território nacional e que avalia as condições dos mesmos, apenas no ano de 2011 e tudo isso em meio à protestos dos cientistas da área. 
Dessa forma, tratar da geomorfodiversidade ainda é muito recente, pois não se tem todos os conceitos definidos em consenso, especialmente em língua portuguesa. (PANIZZA, 2009, p. 41) exprime uma conceituação do que seria geomorfodiversidade, caracterizando

With respect to Geomorphology, geodiversity may be defined with the term geomorphodiversity: "the critical and specific assessment of the geomorphological features of a territory, by comparing them in an extrinsic and in intrinsic way, taking into account the scale of investigation, the purpose of the research and the level of scientific quality.

O objetivo deste trabalho foi quantificar o patrimônio geomorfológico da zona costeira de Icapuí, Ceará, Brasil. Para a consecução deste objetivo foi proposta uma adaptação da técnica de quantificação de Pereira (2010), adaptada ao estudo do patrimônio geomorfológico, partindo da hipótese que pode existir locais com alto valor estético que não apresentam alto valor científico, mas que assim mesmo devem ser prioritários para a geoconservação, dado que estas geoformas têm alto potencial de convencimento para a sociedade em relação à temática da geoconservação, à exemplo de formas icônicas, geralmente consideradas "cartões postais" das áreas onde se situam.

\section{1. Área de estudo}

A área de estudo está inserida no litoral leste do estado do Ceará, mais precisamente no município de Icapuí, situado na Região Imediata de Aracati e Intermediária de Quixadá (IBGE, 2017) - Figura 1. O município localiza-se nas coordenadas geográficas $4^{\circ} 42^{\prime} 47^{\prime \prime} \mathrm{S}$ e $37^{\circ} 21^{\prime} 19^{\prime \prime} \mathrm{O}$, estabelecendo limites com Oceano Atlântico à Norte, munícipio de Aracati e estado do Rio Grande do Norte à Sul, Oceano Atlântico a Leste e Aracati à oeste. Dispondo de uma área de 423,4 Km2 com via de acesso principal pela CE-261 (IPECE, 2017).

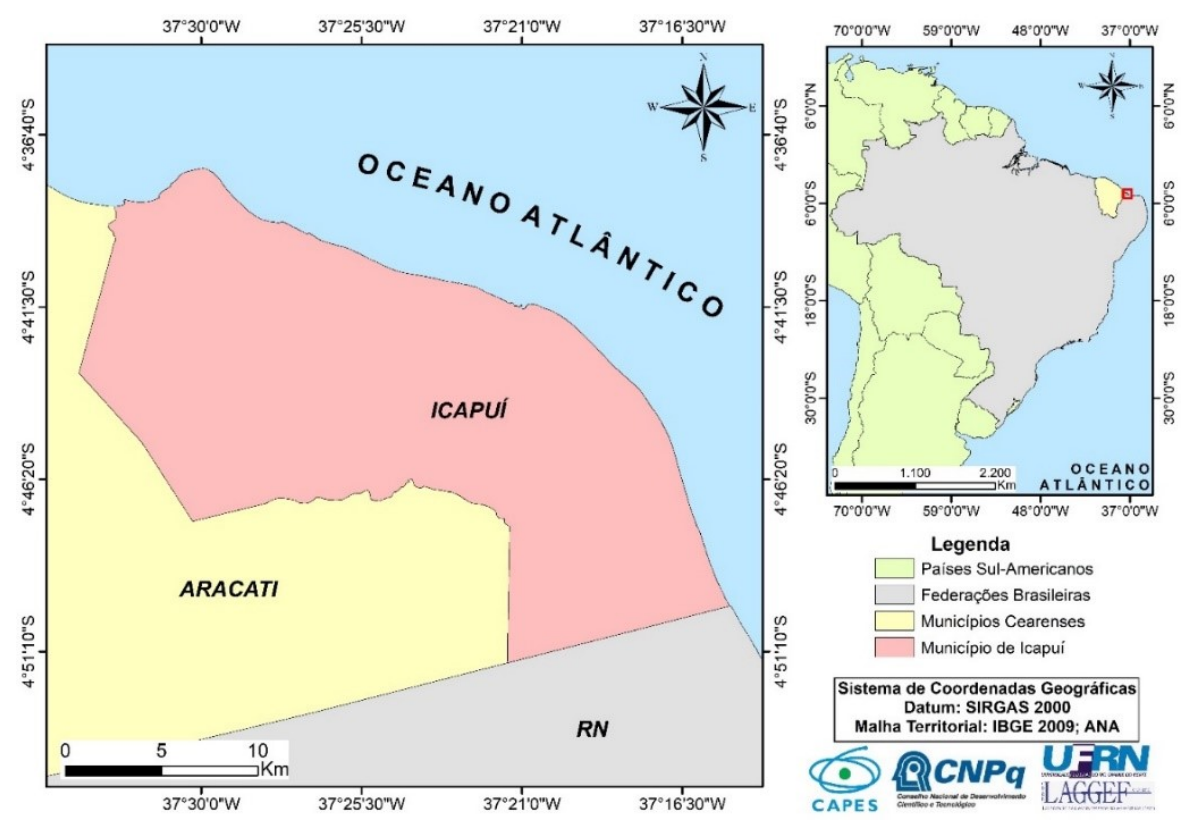

Figura 1 - Mapa de localização do município de Icapuí/CE.

Fonte: Elaborado pelos autores, 2020. 
No município existem duas Áreas de Proteção Ambiental (APA) Municipais, a de Ponta Grossa, criada pela Lei $n^{\circ} .262 / 98$ de 8 de abril de 1998 (ICAPUÍ, 1998) e alterada para Lei $n^{\circ}$ 633/2014 de 25 de fevereiro de 2014 e a da Barra Grande estabelecida a partir da Lei Municipal ${ }^{\circ}$ 298/2000, no dia 12 de maio de 2000 (ICAPUÍ, 2000). E conforme Meireles, Silva e Souza (2017), a lei foi alterada para Lei $\mathrm{n}^{\circ}$ 634/2014, do dia 25 de fevereiro de 2014 (ICAPUÍ, 2014), devido à área inicial ter sido ampliada, correspondendo agora a 18.100 hectares.

\section{MATERIAIS E MÉTODOS}

O método empregado nesta pesquisa foi desenvolvido com a finalidade de quantificar o patrimônio da geomorfodiversidade e diminuir a subjetividade encontrada em fichas de avaliação do geopatrimonio anteriormente desenvolvidas, como alguns dos estudos mais relevantes, como os de Brilha (2005), Reynard (2006), Reynard et. al., (2007), Lopes (2017), entre outros. Diante disso foram realizadas várias adaptações de métodos já existentes, para propor principalmente um direcionamento mais significativo para os valores científico e estético, valores centrais para a definição de geomorfossítios.

A proposta metodológica da avaliação quantitativa está embasada no autor Pereira (2010), que tratou da geoconservação e desenvolvimento sustentável na Chapada da Diamantina, Bahia Brasil. O autor abordou em seu trabalho quatro tipos de valores: o cientifico, intrínseco, turístico e de uso e gestão, porém, entende-se que o segundo valor mencionado está diluído nos demais, pois o valor intrínseco corresponde ao valor por sua própria existência. Dessa forma, foi modificado para a proposição da quantificação do valor estético, que está mais relacionado com a geomorfodiversidade.

Foram utilizados os critérios do Tricart (1977) - ecodinâmica dos meios; Pereira (2006) interesse ecológico; Reynard (2006) e Reynard et. al., (2007) - valor paleogeográfico; Brilha (2016) com itens como diversidade de aspectos geológicos (alterado para aspectos geomorfológicos), condições de observação, cenário, uso limitado e densidade populacional; e Brasil (2020) - categorias turísticas e outras modificações nos parâmetros.

A tabela 1 expõe todos os parâmetros analisados e considerados na proposta metodológica, utilizados por diferentes autores em distintas perspectivas, seja de caráter científico, geoturístico e sobre o próprio patrimônio geomorfológico.

Tabela 1 - Critérios utilizados por diferentes autores para construção metodológica.

\begin{tabular}{ccccccccc}
\hline CRITÉRIOS & $\begin{array}{c}\text { Coratzae } \\
\text { Giusti } \\
(\mathbf{2 0 0 5 )}\end{array}$ & $\begin{array}{c}\text { Reynard } \\
(\mathbf{2 0 0 6})\end{array}$ & $\begin{array}{c}\text { Pereira } \\
\mathbf{( 2 0 0 6 )}\end{array}$ & $\begin{array}{c}\text { Pereira } \\
\mathbf{( 2 0 1 0 )}\end{array}$ & $\begin{array}{c}\text { Oliveira } \\
(\mathbf{2 0 1 5})\end{array}$ & $\begin{array}{c}\text { Pereira; } \\
\text { Nogueira } \\
(\mathbf{2 0 1 5})\end{array}$ & $\begin{array}{c}\text { Brilha } \\
(\mathbf{2 0 1 6})\end{array}$ & $\begin{array}{c}\text { Lopes } \\
(\mathbf{2 0 1 7})\end{array}$ \\
\hline $\begin{array}{c}\text { Grau de } \\
\text { Conhecimento } \\
\text { Científico }\end{array}$ & $\mathrm{X}$ & $\mathrm{X}$ & $\mathrm{X}$ & $\mathrm{X}$ & $\mathrm{X}$ & $\mathrm{X}$ \\
$\begin{array}{c}\text { Ecodinâmica dos } \\
\text { meios }\end{array}$ & & & & & & & \\
\end{tabular}




\begin{tabular}{|c|c|c|c|c|c|c|c|c|}
\hline $\begin{array}{l}\text { Represent. de } \\
\text { materiais e processos } \\
\text { geomorfológicos }\end{array}$ & & $\mathbf{x}$ & $\mathbf{x}$ & $\mathbf{x}$ & & $\mathbf{X}$ & $\mathbf{x}$ & $\mathbf{x}$ \\
\hline $\begin{array}{c}\text { Diversidade de } \\
\text { aspectos } \\
\text { geomorfológicos } \\
\text { (formas e processos) }\end{array}$ & & & $\mathbf{x}$ & & $\mathbf{X}$ & & & \\
\hline Influência Ecológica & & $\mathbf{x}$ & $\mathbf{x}$ & & & $\mathbf{x}$ & & $\mathbf{x}$ \\
\hline $\begin{array}{c}\text { Valor } \\
\text { Paleogeográfico }\end{array}$ & & $\mathbf{X}$ & & & & $\mathbf{x}$ & & $\mathbf{x}$ \\
\hline Relevância Didática & $\mathbf{x}$ & & & $\mathbf{x}$ & $\mathbf{x}$ & $\mathbf{x}$ & $\mathbf{x}$ & $\mathbf{x}$ \\
\hline Raridade & $\mathbf{X}$ & $\mathbf{x}$ & $\mathbf{x}$ & $\mathbf{x}$ & & $\mathbf{x}$ & $\mathbf{x}$ & $\mathbf{x}$ \\
\hline Integridade & & $\mathbf{x}$ & $\mathbf{x}$ & $\mathbf{X}$ & $\mathbf{x}$ & & $\mathbf{x}$ & $\mathbf{x}$ \\
\hline $\begin{array}{c}\text { Variedade de } \\
\text { elementos da } \\
\text { geodiversidade e/ou } \\
\text { temáticas associadas }\end{array}$ & & & & $\mathbf{x}$ & $\mathbf{x}$ & $\mathbf{x}$ & & $\mathbf{x}$ \\
\hline Qualidade Visual & & $\mathbf{x}$ & & & & $\mathbf{x}$ & & \\
\hline $\begin{array}{l}\text { Condições de } \\
\text { observações }\end{array}$ & & & $\mathbf{x}$ & & $\mathbf{x}$ & $\mathbf{X}$ & & $\mathbf{X}$ \\
\hline Acessibilidade & & & $\mathbf{x}$ & $\mathbf{x}$ & $\mathbf{x}$ & $\mathbf{x}$ & $\mathbf{x}$ & $\mathbf{x}$ \\
\hline $\begin{array}{l}\text { Presença de } \\
\text { infraestrutura }\end{array}$ & & & $\mathbf{x}$ & $\mathbf{x}$ & & $\mathbf{x}$ & & $\mathbf{x}$ \\
\hline $\begin{array}{c}\text { Existência de } \\
\text { utilização em curso }\end{array}$ & & & & $\mathbf{X}$ & & & & $\mathbf{X}$ \\
\hline Cenário & & & & & & & $\mathbf{x}$ & \\
\hline \multicolumn{9}{|l|}{ Categoria turística } \\
\hline Uso limitado & & & & & & & $\mathbf{x}$ & \\
\hline Relevância Cultural & & & $\mathbf{x}$ & $\mathbf{x}$ & $\mathbf{x}$ & & & \\
\hline $\begin{array}{l}\text { Relevância } \\
\text { Econômica }\end{array}$ & & & & $\mathbf{X}$ & & & & \\
\hline $\begin{array}{l}\text { Nível de proteção } \\
\text { oficial }\end{array}$ & & & $\mathbf{x}$ & $\mathbf{x}$ & & $\mathbf{X}$ & $\mathbf{x}$ & $\mathbf{x}$ \\
\hline $\begin{array}{c}\text { Vulnerabilidade } \\
\text { associada ao uso } \\
\text { antrópico } \\
\text { Densidade } \\
\text { populacional ou } \\
\text { população do núcleo } \\
\text { urbano mais próximo }\end{array}$ & & & $\mathbf{x}$ & $\mathbf{x}$ & & $\mathbf{x}$ & $\mathbf{x}$ & $\mathbf{x}$ \\
\hline $\begin{array}{c}\text { Condições } \\
\text { socioeconômicas dos } \\
\text { núcleos urbanos mais } \\
\text { próximos }\end{array}$ & & & & $\mathbf{x}$ & & & & \\
\hline
\end{tabular}

Fonte: Elaborado pelos autores.

A avaliação quantitativa ora proposta está dividida em quatro categorias: valor científico (sete parâmetros), valor estético (cinco parâmetros), valor turístico (cinco parâmetros) e valor de uso e gestão (sete parâmetros), totalizando um número de 24 critérios, com uma valoração de 0 a 4 , sendo realizada através de soma, com a mesma importância para todos os parâmetros. Na tabela 02 é possível observar o valor científico, sendo que, nos valores em que não passou de cinco parâmetros, foi substituído por um traço que não possui pontuação. 
Tabela 02: Parâmetros do Valor Científico.

Valor Científico

\begin{tabular}{|c|c|c|c|c|c|c|c|}
\hline Parâmetros & $\begin{array}{l}\text { A1 - Grau de } \\
\text { Conhecimento } \\
\text { Científico }\end{array}$ & $\begin{array}{c}\text { A2- } \\
\text { Ecodinâmica } \\
\text { dos meios }\end{array}$ & $\begin{array}{c}\mathrm{A3} \text { - } \\
\text { Representatividade de } \\
\text { materiais e processos } \\
\text { geomorfológicos }\end{array}$ & $\begin{array}{l}\text { A4 - Diversidade } \\
\text { de aspectos } \\
\text { geomorfológicos } \\
\text { (formas e } \\
\text { processos) }\end{array}$ & $\begin{array}{l}\text { A5 - Interesse } \\
\text { Ecológico }\end{array}$ & $\begin{array}{c}\text { A6 - Valor } \\
\text { Paleogeográfico }\end{array}$ & $\begin{array}{l}\text { A7 - Relevância } \\
\text { Didática }\end{array}$ \\
\hline Definição & $\begin{array}{l}\text { Indica se o sítio } \\
\text { propriamente } \\
\text { dito já foi alvo de } \\
\text { estudos } \\
\text { acadêmicos ou } \\
\text { citado em artigos } \\
\text { técnico- } \\
\text { científicos. }\end{array}$ & $\begin{array}{l}\text { Refere-se à } \\
\text { classificação dos } \\
\text { meios no nível } \\
\text { taxonômico mais } \\
\text { elevado. }\end{array}$ & $\begin{array}{l}\text { Indicativo da relevância } \\
\text { do sítio como registro de } \\
\text { elementos ou processos } \\
\text { relacionados com a } \\
\text { evolução } \\
\text { geomorfológica da } \\
\text { região e o contexto em } \\
\text { que ela se insere, bem } \\
\text { como o aproveitamento } \\
\text { da geomorfologia para a } \\
\text { sociedade. }\end{array}$ & $\begin{array}{l}\text { Elementos da } \\
\text { geomorfologia } \\
\text { que agrega o sítio. }\end{array}$ & $\begin{array}{l}\text { Valoriza-se a relação } \\
\text { entre o(s) objeto(s) } \\
\text { geomorfológico(s) e a } \\
\text { ocorrência de } \\
\text { espécies biológicas; a } \\
\text { pontuação é tanto } \\
\text { maior quanto maior } \\
\text { for a percepção de } \\
\text { relação entre habitats } \\
\text { e geomorfologia. }\end{array}$ & $\begin{array}{l}\text { A importância do } \\
\text { objeto para a } \\
\text { reconstrução da } \\
\text { história do clima e da } \\
\text { Terra (por exemplo, } \\
\text { estágio de referência } \\
\text { glacial) é avaliada por } \\
\text { esse critério. }\end{array}$ & $\begin{array}{l}\text { Potencial do sítio } \\
\text { para ilustrar } \\
\text { elementos ou } \\
\text { processos da } \\
\text { geodiversidade e } \\
\text { possibilidade de } \\
\text { uso do local para } \\
\text { ensino das } \\
\text { geociências por } \\
\text { escolas } \\
\text { secundárias. }\end{array}$ \\
\hline $\mathbf{0}$ & $\begin{array}{l}\text { Inexistência de } \\
\text { qualquer } \\
\text { referência sobre } \\
\text { o sítio. }\end{array}$ & $\begin{array}{l}\text { Meio Estável - } \\
\text { predomínio de } \\
\text { pedogênese. } \\
\text { Meios com lenta } \\
\text { evolução, } \\
\text { cobertura } \\
\text { vegetal fechada, } \\
\text { dissecação } \\
\text { moderada e } \\
\text { ausência de } \\
\text { manifestações } \\
\text { vulcânicas. }\end{array}$ & - & $\begin{array}{l}\text { Sem aspectos } \\
\text { geomorfológicos. }\end{array}$ & $\begin{array}{l}\text { Sem conexão com } \\
\text { elementos biológicos. }\end{array}$ & $\begin{array}{l}\text { Sem qualquer } \\
\text { expressividade } \\
\text { paleogeográfica }\end{array}$ & $\begin{array}{l}\text { Sem relevância } \\
\text { didática. }\end{array}$ \\
\hline 1 & $\begin{array}{l}\text { Citado em um } \\
\text { relatório técnico } \\
\text { ou Monografia. }\end{array}$ & - & $\begin{array}{l}\text { Ausência de qualquer } \\
\text { aspecto relevante de } \\
\text { natureza científica. }\end{array}$ & $\begin{array}{l}\text { Com } 1 \text { aspecto } \\
\text { geomorfológicos. }\end{array}$ & $\begin{array}{l}\text { Ocorrência de fauna } \\
\text { e/ou flora com } \\
\text { interesse. }\end{array}$ & - & $\begin{array}{l}\text { Passível de ser } \\
\text { utilizado para fins } \\
\text { didáticos na Pós- } \\
\text { Graduação. }\end{array}$ \\
\hline 2 & $\begin{array}{lr}\text { Citado em } & 2 \\
\text { monografias } & \text { ou } \\
\text { artigos } & \\
\text { científicos } & \text { ou } \\
\text { dissertação. } & \end{array}$ & $\begin{array}{l}\text { Integrade - área } \\
\text { de transição para } \\
\text { estabilidade - } \\
\text { quando } \quad \text { a } \\
\text { pedogênese } \\
\text { sobressai sobre a } \\
\text { morfogênese. }\end{array}$ & $\begin{array}{l}\text { Abriga registros } \\
\text { ilustrativos de elementos } \\
\text { ou processos da } \\
\text { geodiversidade, mas que } \\
\text { não tenham potencial. }\end{array}$ & $\begin{array}{l}\text { Com } 2 \text { aspectos } \\
\text { geomorfológicos. }\end{array}$ & $\begin{array}{l}\text { Um dos melhores } \\
\text { locais para observar } \\
\text { fauna e/ou flora com } \\
\text { interesse. }\end{array}$ & $\begin{array}{lr}\text { Abriga } & \text { elementos } \\
\text { ilustrativos, mas com } \\
\text { difícil visualização } \\
\text { dos } \quad \text { elementos } \\
\text { paleográficos }\end{array}$ & $\begin{array}{lr}\text { Passível de } & \text { ser } \\
\text { utilizado para fins } \\
\text { didáticos r para } \\
\text { alunos r de } \\
\text { Graduação. }\end{array}$ \\
\hline 3 & $\begin{array}{lrr}\text { Citado em } & 3 \\
\text { teses } & \text { ou } \\
\text { dissertações } & \text { ou } \\
\text { artigo científico. }\end{array}$ & $\begin{array}{l}\text { Intergrade }- \\
\text { área de transição } \\
\text { para } \\
\text { instabilidade } \quad- \\
\text { quando a } \\
\text { morfogênese } \\
\text { sobressai sobre a } \\
\text { pedogênese. }\end{array}$ & $\begin{array}{lr}\text { Abriga elementos } \\
\text { ilustrativos } \\
\text { representam seções tipo } \\
\text { de formações ou } \\
\text { utilizado como } \\
\text { exemplos clássicos mais } \\
\text { interferência antrópica. }\end{array}$ & $\begin{array}{l}\text { Com } 3 \text { aspectos } \\
\text { geomorfológicos. }\end{array}$ & $\begin{array}{l}\text { Características } \\
\text { geomorfológicas } \\
\text { condicionam } \\
\text { ecossistema(s). }\end{array}$ & $\begin{array}{l}\text { Abriga elementos } \\
\text { ilustrativos que } \\
\text { representam evolução } \\
\text { paleogeográfica } \\
\text { podendo ser utilizado } \\
\text { como exemplo com } \\
\text { bom recurso didático } \\
\text { com } \\
\text { descaracterização } \\
\text { humana. }\end{array}$ & $\begin{array}{l}\text { Passível de ser } \\
\text { utilizado para fins } \\
\text { didáticos para } \\
\text { alunos do Ensino } \\
\text { Médio. }\end{array}$ \\
\hline 4 & $\begin{array}{l}\text { Citado em }>4 \\
\text { teses acadêmicas } \\
\text { ou artigos de } \\
\text { revistas } \\
\text { científicas. }\end{array}$ & $\begin{array}{l}\text { Fortemente } \\
\text { Instável } \\
\text { predomínio de } \\
\text { morfogênese. } \\
\text { Meios com } \\
\text { intervenção da } \\
\text { geodinâmica, } \\
\text { através do } \\
\text { vulcanismo, } \\
\text { deformações } \\
\text { tectônicas ou } \\
\text { instabilidade } \\
\text { antrópica. }\end{array}$ & $\begin{array}{l}\text { Abriga elementos } \\
\text { ilustrativos que } \\
\text { representam seções tipo } \\
\text { de formaços ou } \\
\text { utilizado como } \\
\text { exemplos clássicos de } \\
\text { elementos ou processos } \\
\text { geomorfológicos, bom } \\
\text { recurso didático e ou de } \\
\text { utilização de relevo para } \\
\text { a sociedade. }\end{array}$ & $\begin{array}{l}\text { Com } 4 \text { ou mais } \\
\text { aspectos } \\
\text { geomorfológicos. }\end{array}$ & $\begin{array}{l}\text { Características } \\
\text { geomorfológicas } \\
\text { determinam } \\
\text { ecossistema(s). }\end{array}$ & $\begin{array}{l}\text { Abriga elementos } \\
\text { ilustrativos que } \\
\text { representam evolução } \\
\text { paleogeográfica } \\
\text { podendo ser utilizado } \\
\text { como exemplo com } \\
\text { bom recurso didático e } \\
\text { sem a presença de } \\
\text { descaracterização e } \\
\text { cobertura vegetal, } \\
\text { possibilitando uma } \\
\text { excelente visualização } \\
\text { dos elementos } \\
\text { geomorfológicos }\end{array}$ & $\begin{array}{l}\text { Passível de ser } \\
\text { utilizado para fins } \\
\text { didáticos para um } \\
\text { público geral ou } \\
\text { alunos de Ensino } \\
\text { Fundamental. }\end{array}$ \\
\hline
\end{tabular}

Fonte: Adaptado de Tricart (1977), Pereira (2006), Reynard (2006), Reynard et al., (2007), Pereira (2010) e Brilha (2016).

O cálculo da categoria do Valor Científico (VCi) é expressa na Equação 1:

$$
\mathrm{VCi}=\mathrm{A} 1+\mathrm{A} 2+\mathrm{A} 3+\mathrm{A} 4+\mathrm{A} 5+\mathrm{A} 6+\mathrm{A} 7
$$

Na tabela 03 são apresentados os parâmetros e definições para o valor estético. 
Tabela 03 - Parâmetros do Valor Estético.

\begin{tabular}{|c|c|c|c|c|c|}
\hline \multicolumn{6}{|c|}{ VALOR ESTÉTICO } \\
\hline Parâmetros & B1 - Raridade & B2 - Integridade & $\begin{array}{l}\text { B3 - Variedade de elementos } \\
\text { da geodiversidade e/ou } \\
\text { temáticas associadas }\end{array}$ & B4 - Qualidade Visual & $\begin{array}{l}\text { B5 - Condições de } \\
\text { observações }\end{array}$ \\
\hline Definição & $\begin{array}{l}\text { Importância do sítio em } \\
\text { termos de sua ocorrência } \\
\text { geomorfológica na área } \\
\text { investigada. }\end{array}$ & $\begin{array}{l}\text { Indicativo do nível de } \\
\text { conservação do geomorfossítio } \\
\text { e da possibilidade de } \\
\text { visualização dos aspectos de } \\
\text { interesse. }\end{array}$ & $\begin{array}{l}\text { Quantidade de interesses e } \\
\text { elementos da geodiversidade e } \\
\text { temáticas associadas ao } \\
\text { patrimônio geomorfológico } \\
\text { (hidrologia, } \\
\text { mineralogia, hidrogeologia, } \\
\text { oceanografia, hidrografia, etc.). }\end{array}$ & $\begin{array}{l}\text { Relativo à beleza cênica do } \\
\text { local. Medido a partir da } \\
\text { verticalidade, contraste de } \\
\text { cores e elementos individuais } \\
\text { (inselbergs, yardangs, relevos } \\
\text { ruineformes e etc) }\end{array}$ & $\begin{array}{lr}\text { Condição } & \text { de } \\
\text { visualização } & \text { dos } \\
\text { elementos } & \text { da } \\
\text { geodiversidade. } & \end{array}$ \\
\hline $\mathbf{0}$ & $\begin{array}{l}\text { Sítio de ocorrência comum } \\
\text { na área da investigação } \\
\text { (mais de } 10 \text { ocorrências) em } \\
\text { um raio de } 200 \mathrm{Km} \text {. }\end{array}$ & $\begin{array}{l}\text { Sítio deteriorado e } \\
\text { descaracterizado, de maneira } \\
\text { que a observação dos elementos } \\
\text { de interesse } \\
\text { comprometidas estejam } \\
\text { possibilidade de recuperação. }\end{array}$ & Nenhuma associação & $\begin{array}{l}\text { Sítio sem qualquer relevância } \\
\text { estética. }\end{array}$ & $\begin{array}{l}\text { Sem condições de } \\
\text { visualização. }\end{array}$ \\
\hline 1 & $\begin{array}{l}\text { Entre } 6 \text { e } 10 \text { exemplares } \\
\text { com } \\
\text { similares na área, dentro do } \\
\text { mesmoracterísticas } \\
\text { geomorfológico em um raio } \\
\text { de } 200 \mathrm{Km} \text {. contexto }\end{array}$ & $\begin{array}{l}\text { Sítio deteriorado, porém ainda } \\
\text { permite a visualização dos } \\
\text { aspectos de interesse, } \\
\text { possibilidade } \\
\text { recuperado. }\end{array}$ & $\begin{array}{l}\text { Associação com apenas um } \\
\text { elemento ou temática associada a } \\
\text { geodiversidade. }\end{array}$ & $\begin{array}{l}\text { Sítio inserido em local } \\
\text { aprazível e dotado de algum } \\
\text { elemento individual. }\end{array}$ & $\begin{array}{l}\text { Apenas visível com } \\
\text { equipamentos. }\end{array}$ \\
\hline 2 & $\begin{array}{l}\text { Existência de até } 5 \\
\text { exemplares } \\
\text { características similares na } \\
\text { área, dentro do mesmo } \\
\text { contexto geomorfológico } \\
\text { em um raio de } 200 \mathrm{Km} \text {. }\end{array}$ & $\begin{array}{l}\text { Sítio deteriorado, porém ainda } \\
\text { permite a visualização dos } \\
\text { aspectos de interesse com } \\
\text { possibilidade de recuperação. }\end{array}$ & $\begin{array}{l}\text { Associação com dois elementos } \\
\text { ou temáticas associadas a } \\
\text { geodiversidade. }\end{array}$ & $\begin{array}{l}\text { Sítio inserido em local } \\
\text { aprazivel, dotado de apelo } \\
\text { cênico. Com verticalidade } \\
(<50 \mathrm{~m}) \text { ou contraste de cores } \\
\text { de quatro cores ou mais. }\end{array}$ & $\begin{array}{l}\text { Limitado } \\
\text { vegetação. }\end{array}$ \\
\hline 3 & 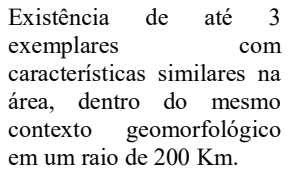 & $\begin{array}{l}\text { Sítio com alguma deterioração, } \\
\text { porém permite a visualização } \\
\text { dos aspectos de interesse e com } \\
\text { possibilidade de ser } \\
\text { recuperado. }\end{array}$ & $\begin{array}{l}\text { Associação com três elementos ou } \\
\text { temáticas associadas a } \\
\text { geodiversidade. }\end{array}$ & $\begin{array}{l}\text { Sítio inserido em local } \\
\text { aprazível, dotado de apelo } \\
\text { cênico. Com verticalidade } \\
(>50 \mathrm{~m}) \text {, relevo montanhoso e } \\
\text { contraste de quatro cores ou } \\
\text { mais. }\end{array}$ & $\begin{array}{l}\text { Boa, mas apenas } \\
\text { observável a partir } \\
\text { da base. }\end{array}$ \\
\hline 4 & $\begin{array}{l}\text { Exemplar único na área em } \\
\text { um raio de } 200 \mathrm{Km} \text { ou } \geq 3 \\
\text { com raio de } 500 \mathrm{Km} .\end{array}$ & $\begin{array}{l}\text { Sítio íntegro e sem qualquer } \\
\text { deterioração e sem necessidade } \\
\text { de recuperação. }\end{array}$ & $\begin{array}{l}\text { Associação com mais de quatro } \\
\text { elementos ou temáticas } \\
\text { associadas a geodiversidade. }\end{array}$ & 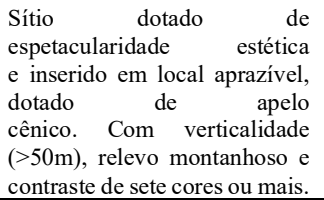 & $\begin{array}{l}\text { Boa, paisagem com } \\
\text { verticalidade e } \\
\text { visível por mirante. }\end{array}$ \\
\hline
\end{tabular}

Fonte: Adaptado de Reynard (2006), Reynard et al., (2007), Pereira (2010) e Brilha (2016).

O valor estético é um dos mais discutidos em uma avaliação quantitativa, devido a sua subjetividade, pois nem todos apreciam a paisagem da mesma forma. Tendo em vista que o patrimônio geomorfológico apresenta um caráter cênico, é necessário caracterizar e avaliar sua estética, de acordo com a espetacularidade, representado como parâmetro na qualidade visual. Diante disso, conforme menciona Pereira (2006) e Lopes (2017), o valor estético é representado principalmente pela sua dimensão, estado de conservação, contraste de elementos geomorfológicos e cores, presença de água e interação com outros elementos. Contudo, o parâmetro espetacularidade é derivada principalmente de dois outros parâmetros relevantes: o contraste de cores e a verticalidade.

O contraste de cores na avaliação é mensurado a partir de um documento icnográfico, em que é capturado o RGB das cores contrastantes do sítio através de programas de computadores e a verticalidade é medida pelo GPS (Sistema de Posicionamento Global).

Dupont, Antrop e Van Eetvelde (2013) afirmaram que paisagens heterogêneas, isto é, que contenham uma diversidade de fatores, seja contraste de cores, presença de elementos individuais, água, verticalidade, vegetação, entre outros, se tornam mais divertidas para as pessoas. Dessa maneira, a partir da visão dos autores mencionados é possível inferir que esses locais sejam mais 
procurados do que paisagens mais monótonas. Estas proposições foram incorporadas à técnica de valoração estética deste trabalho com buscando reduzir substancialmente a subjetividade, estabelecendo, tanto quanto possível, o máximo de objetividade a quantificação do valor estético.

O valor estético (VEst) é expresso pela Equação 2:

$$
\mathrm{VEst}=\mathrm{B} 1+\mathrm{B} 2+\mathrm{B} 3+\mathrm{B} 4+\mathrm{B} 5
$$

Na tabela 04 são apresentados os parâmetros e definições para o valor turístico.

Tabela 04: Parâmetros do Valor Turístico.

\begin{tabular}{|c|c|c|c|c|c|}
\hline \multicolumn{6}{|c|}{ VALOR TURÍSTICO } \\
\hline Parâmetros & C1 - Acessibilidade & C2 - Presença de infraestrutura & $\begin{array}{l}\text { C3 - Existência de } \\
\text { utilização em curso }\end{array}$ & C4 - Cenário & $\begin{array}{l}\text { C5 - Categoria } \\
\text { turística }\end{array}$ \\
\hline Definição & $\begin{array}{c}\text { Indicativo das } \\
\text { dificuldades de acesso } \\
\text { ao local. }\end{array}$ & $\begin{array}{c}\text { Indicativo da presença de } \\
\text { infraestruturas que facilitem e } \\
\text { sirvam de apoio para a utilização } \\
\text { do local, como a presença de } \\
\text { banheiros, guias turísticos, } \\
\text { hospedagem }(>3 \mathrm{Km}) \text {, restaurantes } \\
(>3 \mathrm{Km}) \text { e outros. }\end{array}$ & $\begin{array}{l}\text { Indica as condições atuais } \\
\text { de utilização turística do } \\
\text { sítio. }\end{array}$ & $\begin{array}{c}\text { Utilização em campanhas } \\
\text { turísticas } \\
\text { locais/nacionais/internacionais. }\end{array}$ & $\begin{array}{c}\text { As finalidades de } \\
\text { turismo existentes } \\
\text { na área (sol e praia, } \\
\text { geoturismo, cultural, } \\
\text { religioso, etc.). }\end{array}$ \\
\hline $\mathbf{0}$ & $\begin{array}{l}\text { Acessível a partir de } \\
\text { trilha com mais de } 5 \mathrm{~km} \\
\text { de extensão ou áreas } \\
\text { com obras de contenção. }\end{array}$ & Ausência de qualquer infraestrutura & $\begin{array}{c}\text { Sítio sem qualquer uso } \\
\text { atual. }\end{array}$ & Não aparece em campanhas. & - \\
\hline 1 & $\begin{array}{l}\text { Acessível a partir de } \\
\text { trilha com } 2 \text { a } 5 \mathrm{~km} \text { de } \\
\text { extensão ou a partir do } \\
\text { acesso a área } \\
\text { privatizada. }\end{array}$ & $\begin{array}{l}\text { Dotado de infraestrutura básica, } \\
\text { mas que serve de apoio ao } \\
\text { visitante, com a presença de } 1 \\
\text { elemento. }\end{array}$ & $\begin{array}{l}\text { Sítio com alguma taxa de } \\
\text { visitação, porém ainda } \\
\text { incipiente. }\end{array}$ & Ocasionais em campanhas locais. & $\begin{array}{l}\text { O sítio apresenta um } \\
\text { tipo de turismo }\end{array}$ \\
\hline 2 & $\begin{array}{l}\text { Acessível a partir de } \\
\text { estradas não } \\
\text { pavimentadas ou trilha } \\
\text { com menos de } 2 \mathrm{~km} \text { de } \\
\text { extensão. }\end{array}$ & $\begin{array}{c}\text { Dotado de infraestrutura básica, } \\
\text { mas que serve de apoio ao } \\
\text { visitante, com a presença de } 2 \\
\text { elementos. }\end{array}$ & $\begin{array}{l}\text { Sítio com média taxa de } \\
\text { visitação e presença de } \\
\text { hospedagens. }\end{array}$ & Frequente em campanhas locais. & $\begin{array}{l}\text { O sítio apresenta } \\
\text { dois tipos de } \\
\text { turismo }\end{array}$ \\
\hline 3 & $\begin{array}{l}\text { Acessível a partir de } \\
\text { estradas pavimentadas } \\
\text { ou trilha com menos de } \\
2 \mathrm{~km} \text { de extensão. }\end{array}$ & $\begin{array}{c}\text { Dotado de infraestrutura básica, } \\
\text { mas que serve de apoio ao } \\
\text { visitante, com a presença de } 3 \\
\text { elementos. }\end{array}$ & $\begin{array}{l}\text { Sítio com alta taxa de } \\
\text { visitação, porém } \\
\text { sem mecanismo de } \\
\text { controle de visitantes e } \\
\text { com a presença de } \\
\text { hospedagens. }\end{array}$ & $\begin{array}{c}\text { Ocasional em campanhas } \\
\text { nacionais. }\end{array}$ & $\begin{array}{l}\text { O sítio apresenta } \\
\text { três tipos de turismo }\end{array}$ \\
\hline 4 & $\begin{array}{c}\text { Acessível diretamente } \\
\text { através de estradas } \\
\text { principais (federais, } \\
\text { estaduais ou municipais) } \\
\text { pavimentadas. }\end{array}$ & $\begin{array}{c}\text { Dotado de infraestrutura plena que } \\
\text { prestem todo o apoio ao visitante, } \\
\text { com a presença de } 4 \text { ou mais } \\
\text { elementos. }\end{array}$ & $\begin{array}{l}\text { Sítio com elevada taxa de } \\
\text { visitação e dotado de } \\
\text { medidas de controle de } \\
\text { visitantes e com presença } \\
\text { de meios de hospedagem a } \\
\text { menos de } 3 \mathrm{Km} \text {. }\end{array}$ & $\begin{array}{c}\text { Ocorrentes em campanhas } \\
\text { nacionais. }\end{array}$ & $\begin{array}{l}\text { O sítio apresenta } \\
\text { mais de } 4 \text { tipos de } \\
\text { turismo. }\end{array}$ \\
\hline
\end{tabular}

Fonte: Pereira (2010), Brilha (2016) e Brasil (2020).

Um dos tópicos acrescentados para este valor, foi a categoria turística, que representa a quantidade de tipos de turismo que ocorre em cada sítio, embasado no Plano Nacional de Turismo 2018-2022 (BRASIL, 2020). Os demais, generalizando, retratam o que a área pode oferecer para os turistas ou público em geral. Segue a Equação 3 do valor turístico (VEtur):

$$
\text { VTur }=\mathrm{C} 1+\mathrm{C} 2+\mathrm{C} 3+\mathrm{C} 4+\mathrm{C} 5
$$

O valor de uso e gestão seguiu a base do trabalho de Pereira (2010), com acréscimo de colocações de Brilha (2016) como a densidade populacional, que explanou principalmente como um 
sítio consegue gerir o seu território e suas condições socioeconômicas e da Lei $\mathrm{N}^{\circ}$ 9.985, de 18 de julho de 2000, relativo as unidades de conservação (BRASIL, 2000).

Nos sítios foi levado em consideração o potencial de pesca que está relacionado com o porto que fica no continente e que se encontram as jangadas e barcos para a atividade pesqueira, mas o limite do sítio não se estendendo no âmbito marinho.

Na tabela 05 podemos observar o valor de uso e gestão.

Tabela 05: Parâmetros do Valor de Uso e Gestão.

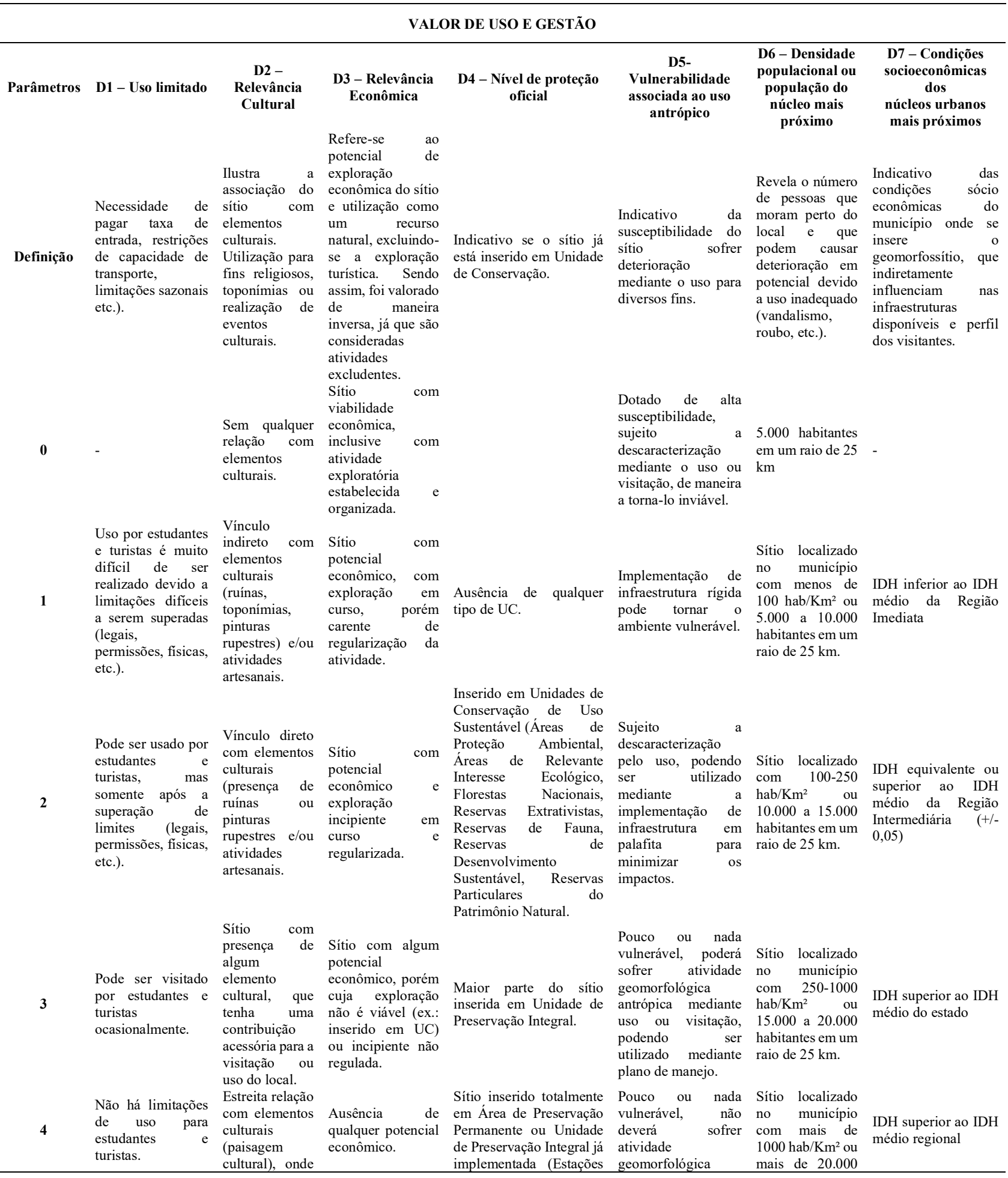




$\begin{array}{lrlrrr}0 & \text { aspecto } & \text { Ecológicas, Reservas } & \text { antrópica mediante habitantes em um } \\ \text { cultural } & \text { seja } & \text { Biológicas, Parques } & \text { uso ou visitação, raio de } 25 \mathrm{~km} . \\ \text { um } & \text { dos } & \text { Nacionais, Monumentos } & \text { podendo } & \text { ser } & \\ \text { principais } & & \text { Naturais e Refúgios de } & \text { utilizado } & \text { sem } \\ \text { atrativos } & \text { da } & \text { Vida Silvestre). } & \text { qualquer restrição. } & \end{array}$

área.

Fonte: Adaptado de Brasil (2000), Pereira (2010) e Brilha (2016).

Foi utilizado o cálculo da equação 4, para quantificar o Valor de Uso e Gestão (VUG).

$$
\mathrm{VUG}=\mathrm{D} 1+\mathrm{D} 2+\mathrm{D} 3+\mathrm{D} 4+\mathrm{D} 5+\mathrm{D} 6+\mathrm{D} 7
$$

A seguir, há um novo cálculo que consiste em outros dois indicadores que são o valor geomorfológico e o valor de gestão (PEREIRA, 2006), ambos realizados por média aritmética. O primeiro é calculado pela média dos valores científico e estético; e o segundo pelos valores turísticos e de uso e gestão, conforme é evidenciado nas equações 5 e 6 :

$$
\begin{aligned}
& V G m=\frac{(\text { Vci }+ \text { Vest })}{2} \\
& V G t=\frac{(\text { Vtur }+ \text { VUG })}{2}
\end{aligned}
$$

Posteriormente, todos os resultados foram tabulados, isto é, valores, parâmetros e valor total (soma do valor geomorfológico com o de gestão) e acrescentado também, o Ranking Final (RK), assim como foi desenvolvido por Pereira (2006). Esse processo consiste em computar quantas posições cada sítio obtém, e a finalidade é valorar os locais que tenham o menor valor na soma, pois significa que eles estiverem nas primeiras colocações nos diferentes aspectos avaliados.

Um local de interesse só será considerado de alto valor se estiver no quartil superior da quantificação, ou seja, maior ou igual a $75 \%$ da pontuação, sendo entre 22 e 28 pontos no caso dos valores científico e de uso e gestão; e entre 16 e 20 pontos nos valores estético e turístico. Consideramse os valores científico e estético como valores centrais, assim, são geomorfossítios os locais de interesse que tenham alto valor científico e/ou estético. Esta proposição corrobora o conceito de Reynard et al., (2007) que considera geomorfossítio apenas os locais de alto valor científico, contudo acredita-se que as geoformas de alto valor estético se caracterizam como geomorfossítios.

Os sítios exibiram valores médios (valor maior que $50 \%$ e menor que $75 \%$ ) na valoração científica, estética, turística e de uso e gestão, ou alto valor nos dois últimos valores, foram denominados como sítio da geomorfodiversidade, assim como foi mencionado por Brilha (2016) para o patrimônio geológico. Os valores baixos ou muito baixos (valor $<50 \%$ ) evidenciaram que os locais representam sítios comuns na área de estudo, não tendo prioridade para a geoconservação. 
A partir dos resultados da avaliação quantitativa foi realizado um mapeamento síntese, embasado na metodologia de Reynard et al., (2016), evidenciando os geomorfossítios e sítios da geomorfodiversidade, bem como os sítios que têm alto no valor turístico ou de uso e gestão.

\section{RESULTADOS E DISCUSSÕES}

Com a investigação prévia da área, por meio de artigos, dissertações, teses, livros e mapeamentos foi possível identificar cinco sítios com interesse geomorfológico, que foram as Praias de Ponta Grossa, Redonda/Peroba, Requenguela, Manibu e o Mirante da Serra do Mar, estes locais são também de visitação turística significativa no município de Icapuí/CE.

Através da pesquisa de campo realizada, observou-se outros locais com representatividade no território municipal que foram o Sítio Retirinho, com falésias ativas que representam testemunhos da existência de neotectônica; a Praia de Picos/Vila Nova, que exibe um yardang, comum apenas em áreas desérticas e formado pela ação do vento sobre a Formação Barreiras; e por fim, o Mirante do Icapuí, que conta com uma gruta erguida pela população local utilizando laterita e rochas do calcário Jandaíra sobre a paleofalésia, local de devoção para a população local.

\subsection{Valor Científico (Vci)}

O primeiro parâmetro avaliado na categoria do valor científico é o grau de conhecimento (A1), relativo a contabilização de publicações com o nome direto do local no título das pesquisas. Dessa forma, o valor máximo da avaliação foi posto para as Praias de Ponta Grossa (Figura 2), apresentando 12 publicações científicas, sendo cinco dissertações, cinco artigos científicos e dois anais e a Redonda/Peroba (Figura 3), citada em oito publicações acadêmicas, sendo três dissertações, três artigos científicos e dois trabalhos de conclusão de curso.

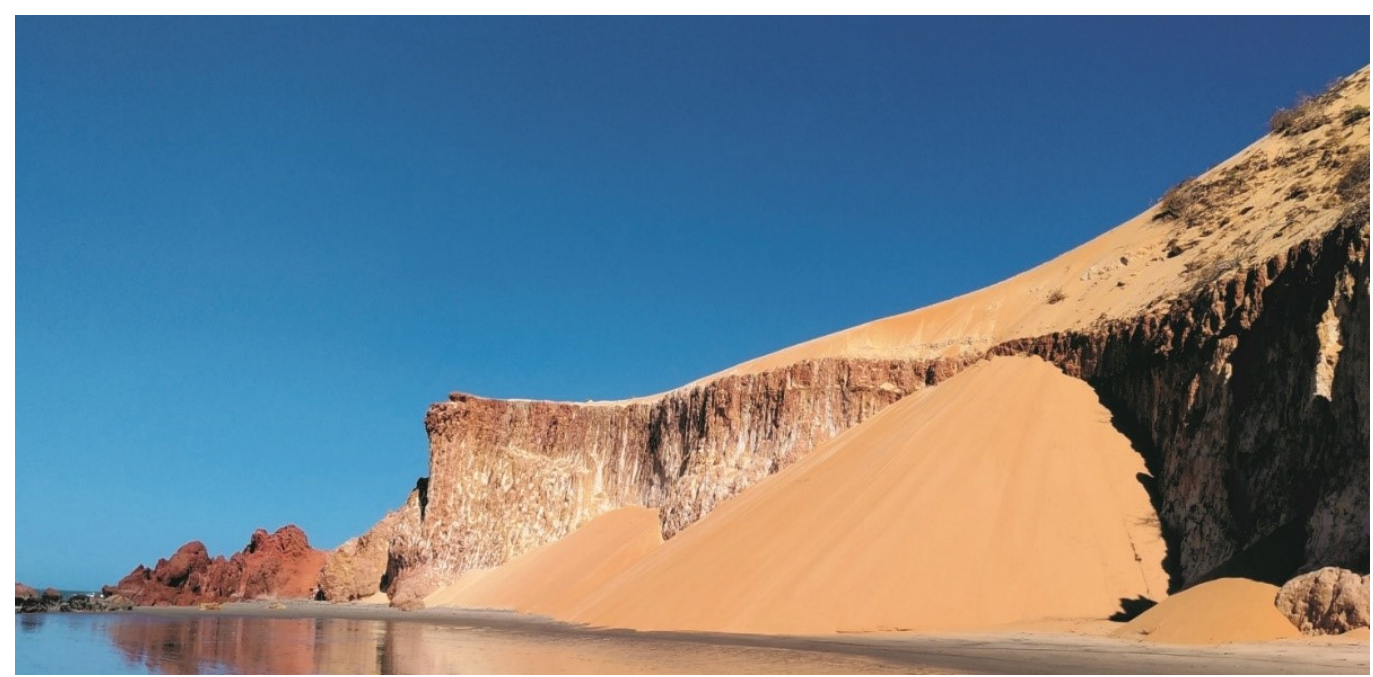

Figura 2 - Praia de Ponta Grossa Fonte: Diniz, 2019. 
A Praia de Requenguela (Figura 4), recebeu o valor 2, exibindo duas produções científicas, sendo um artigo científico e um trabalho de conclusão de curso, enquanto as Praias de Picos/Vila Nova (Figura 5) só foram mencionadas em uma monografia (valor 1) e o Sítio Retirinho (Figura 6), os Mirantes da Serra do Mar (Figura 7), e do Icapuí (Figura 8), e a Praia de Manibu (Figura 9), expressaram inexistência de qualquer referência bibliográfica pelo Google Acadêmico, recebendo a pontuação de 0 (Tabela 06).

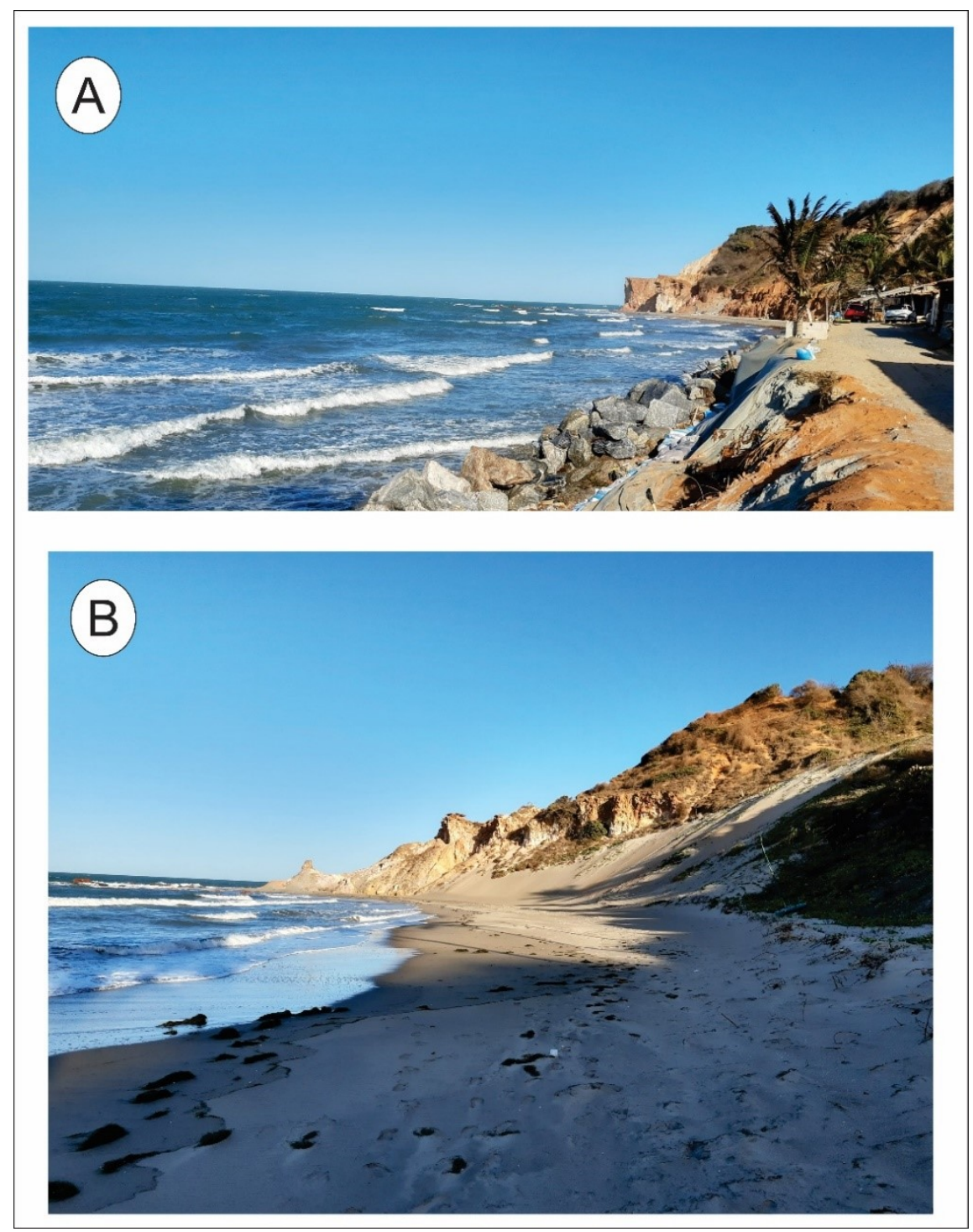

Figura 03 - Praias da Redonda (A) e Peroba (B).

Fonte: Elaborado pelos autores.

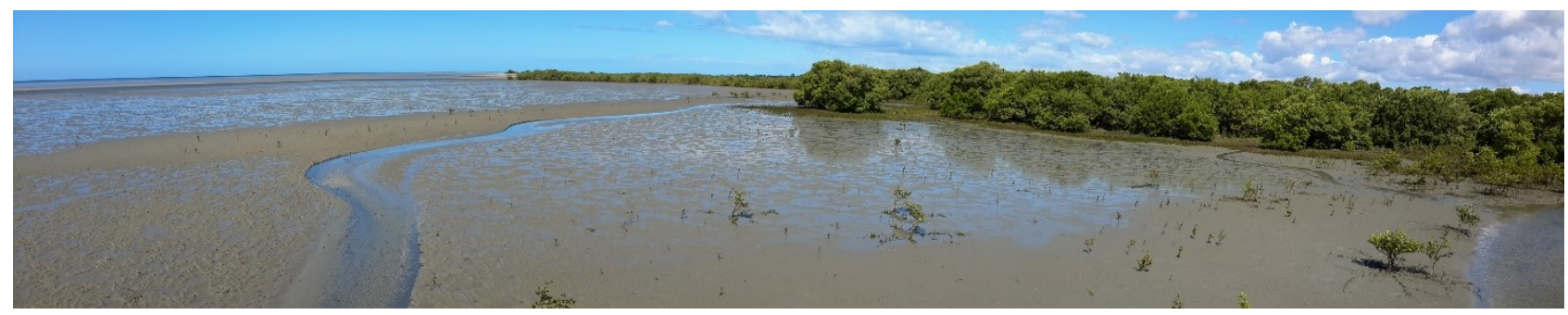

Figura 4 - Praia de Requenguela.

Fonte: Acervo dos autores (2019). 
Tabela 06: Total de publicações científicas dos sítios de interesse geomorfológico de Icapuí/CE.

\begin{tabular}{cccc}
\hline POSIÇÃO & SítiOS & $\begin{array}{c}\text { TOTAL DE } \\
\text { PUBLICAÇÕES }\end{array}$ & MODALIDADES \\
\hline $\mathbf{1}^{\circ}$ & Praia de Ponta Grossa & $\mathbf{1 2}$ & $\begin{array}{c}\text { Artigos científicos, dissertações e anais } \\
\mathbf{2}^{\circ}\end{array}$ \\
& Praias da Redonda/Peroba & $\mathbf{8}$ & Artigos científicos, dissertações e trabalhos de conclusão de \\
curso & \\
$\mathbf{3}^{\circ}$ & Praia de Requenguela & $\mathbf{2}$ & Artigo científico e trabalho de conclusão de curso \\
$\mathbf{4}^{\circ}$ & Praia de Picos/Vila Nova & $\mathbf{1}$ & Monografia \\
$\mathbf{5}^{\circ}$ & Sítio Retirinho & $\mathbf{0}$ & $\mathrm{X}$ \\
$\mathbf{6}^{\circ}$ & Mirante da Serra do Mar & $\mathbf{0}$ & $\mathrm{X}$ \\
$\mathbf{7}^{\circ}$ & Mirante da Gruta do Icapuí & $\mathbf{0}$ & $\mathrm{X}$ \\
\end{tabular}

Fonte: Elaborado pelos autores.

O segundo parâmetro avaliado é a ecodinâmica dos meios (A2) que representa um aspecto importante para a percepção do grau de vulnerabilidade natural de cada sítio, assim, a pontuação máxima (4) foi destinada para os locais fortemente instáveis, quando a morfogênese predomina. Assim sendo, o Sítio Retirinho, as Praias de Ponta Grossa, Redonda/Peroba, Picos/Vila Nova, Requenguela e Manibu são os locais mais instáveis da área estudada, pois são praias oceânicas, que sofrem constantemente com a variação do nível do mar e onde à presença de falésias ativas há a ocorrência da abrasão marinha, e também sucede processos morfodinâmicos constantes.A representatividade de materiais e processos geomorfológicos (A3) obteve valor máximo (4) em quatro sítios, abrigando elementos ilustrativos que representam seções tipo de formações ou utilizado como exemplos clássicos de elementos ou processos geomorfológicos, bom recurso didático e ou de utilização de relevo para a sociedade. Os locais que obtiveram essa pontuação foram o Sítio Retirinho - agrega formações litológicas mais antigas na área, isto é, as formações Jandaíra e Tibau, assim como o Grupo Barreiras e a Formação Potengi -, e as Praias de Ponta Grossa - praia arenosa, com diversas linhas de terraços marinhos que evidenciam as flutuações do nível do mar ocorridas no Quaternário , Requenguela - um delta de maré bastante raso e em progradação devido à baixa energia das ondas na área - e Picos/Vila Nova - que expõe um cânion formado nas falésias e também a formação do Yardang por corrosão da ação eólica, além de diversas falhas e dobramentos nas falésias que ilustram a neotectônica da área. 

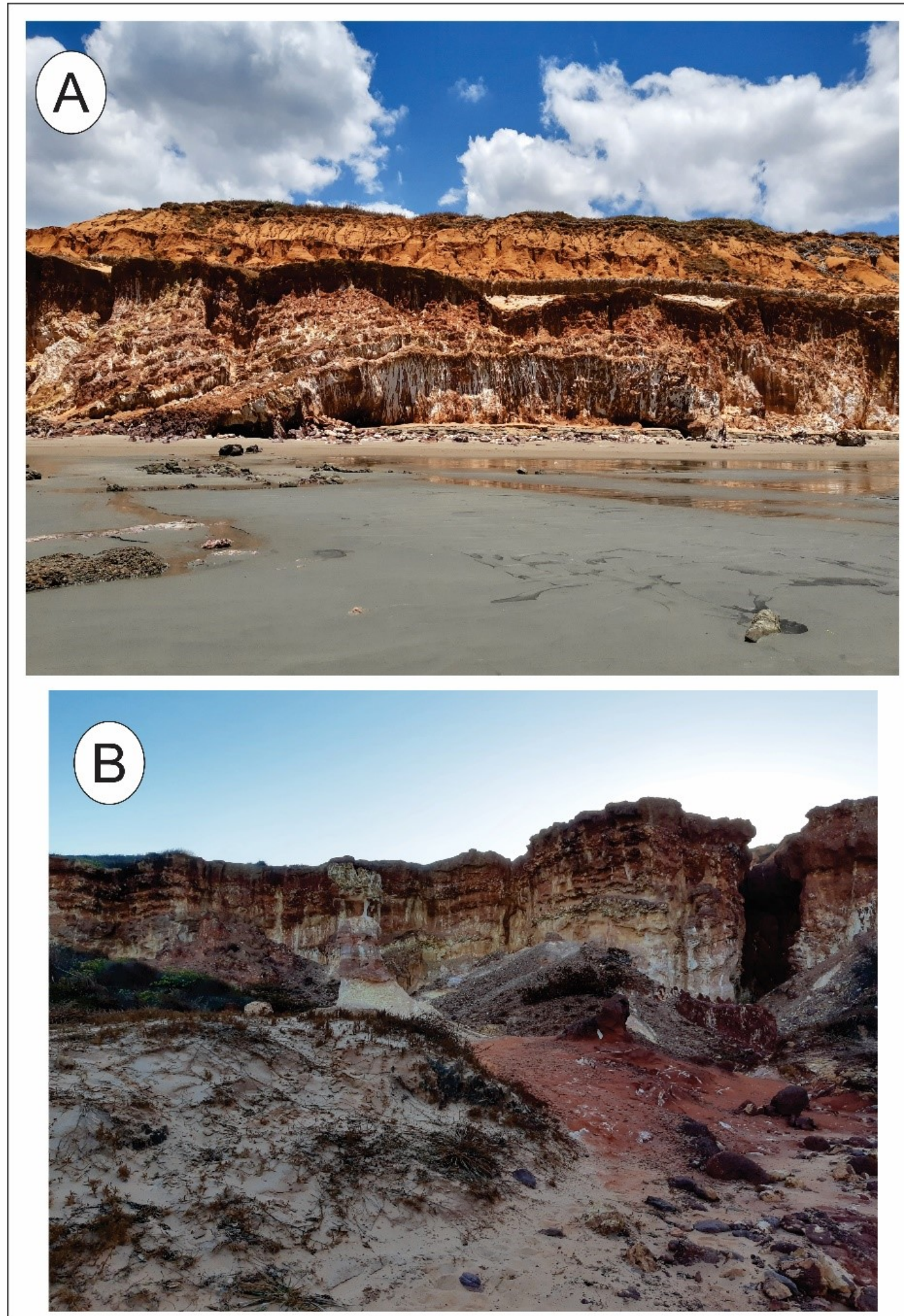

Figura 05 - Vila Nova (A) e Praia de Picos (B).

Fonte: Elaborados pelos autores, 2019.

Os demais sítios receberam o valor 3 pois abrigam elementos ilustrativos e didáticos mas apresentam interferência antrópica, que é a Praia da Redonda/Peroba - representada por falésias, com mosqueamento, interação com campo de dunas, mas com presença de urbanizações -, o Mirante da Serra do Mar - com destaque para os terraços marinhos que representam as flutuações do nível do mar no período do Quaternário e a paleofalésia, as antigas linhas de costa são visíveis mas com 
presença de urbanizações -, Mirante da Gruta do Icapuí - com semelhança ao sítio anterior, mas, com intensa urbanização - e a Praia de Manibu - exemplo clássico de uma praia arenosa, mas com intensa urbanização.

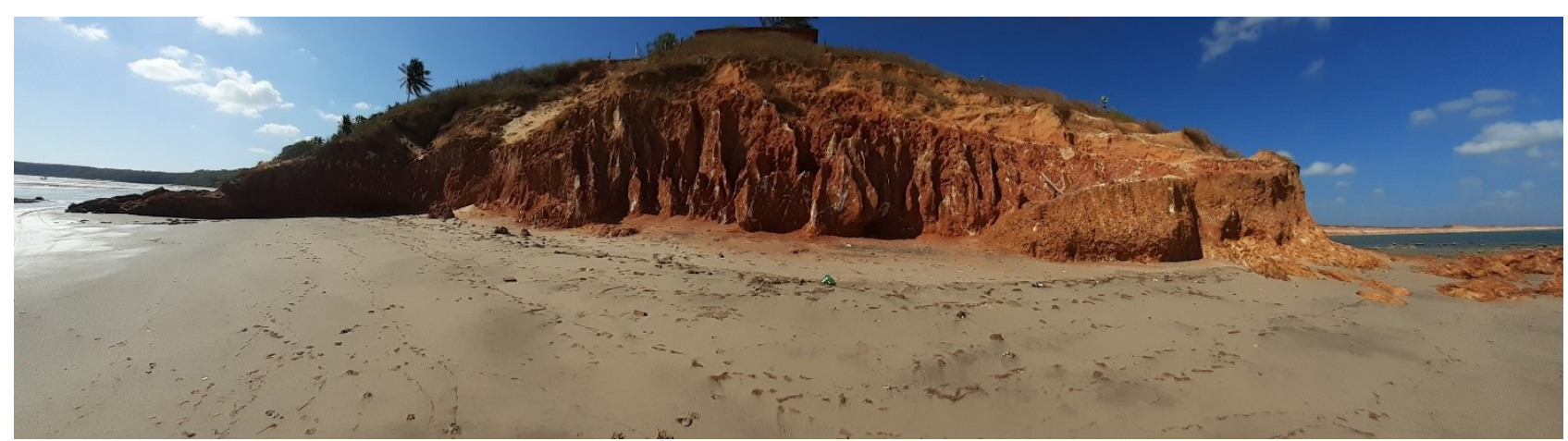

Figura 6 - Sítio Retirinho.

Fonte: Acervo dos autores, 2020.

A diversidade de aspectos geomorfológicos (formas e processos) - A4 apresentou valor máximo (4) em todos os sítios, exibindo quatro ou mais elementos, na Praia de Ponta Grossa (falésia, laguna, barreiras arenosas, intemperismo, movimento de massa, transporte, praia e outros); Redonda/Peroba (falésia, praia, intemperismo, movimento de massas, voçoroca, canelura e outros); Picos/Vila Nova (falésia, cânion, vale, yardang, intemperismo, ravinas e outros); Barrinha/Requeguela (deposição, mangue, terraços marinhos, transporte e outros), Sítio Retirinho (praia, falésia, canelura, intemperismo, ravinas, e outros); Manibu (praia, transporte, deposição, acumulação e outros); os Mirantes da Serra do Mar e da Gruta do Icapuí (terraço marinho, paleofalésia, intemperismo, transporte e outros).

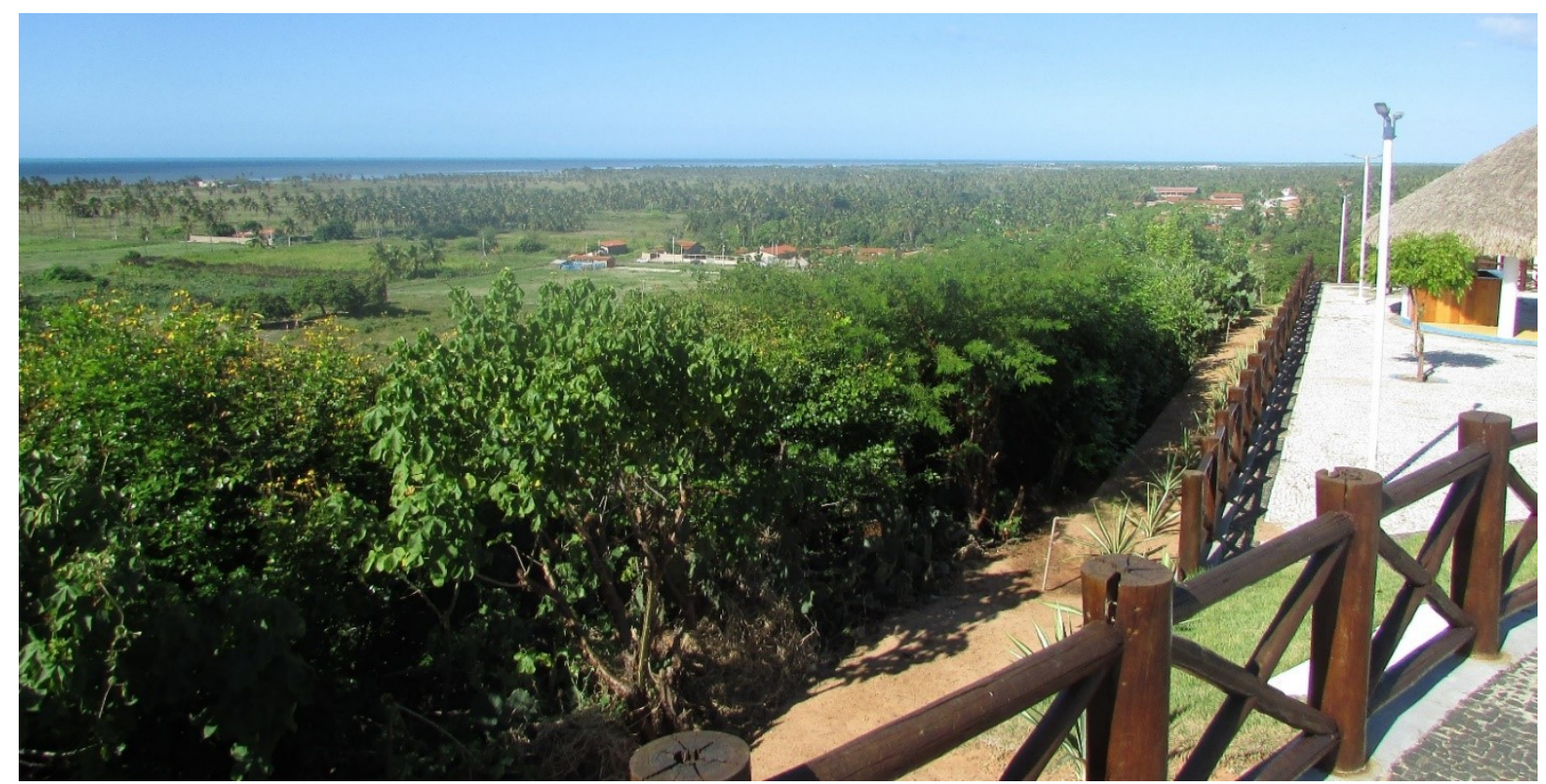

Figura 7 - Mirante da Serra do Mar.

Fonte: Acervo dos autores, 2019. 
O interesse Ecológico (A5) representa a relação de elementos biológicos com a geomorfodiversidade, dessa forma os sítios com a maior pontuação (Valor 4) foram as praias de Manibu (vegetação) e Requenguela (manguezal), assim como o Sítio Retirinho (vegetação), pois as características geomorfológicas determinam os ecossistemas existentes nesses locais. As Praias de Picos/Vila Nova foram pontuadas com o valor 3 , referente às particularidades que condicionam 0 local, já as praias da Redonda/Peroba (Valor 2) é um dos melhores locais da área para observar fauna e flora com interesse. Por fim, a Praia de Ponta Grossa foi avaliada com valor 1, pois à ocorrência de fauna e/ou flora com interesse, vistas na trilha de atalho, com especificações para algumas espécies vegetais, tal como os Mirantes da Serra do Mar e da Gruta do Icapuí, sendo que a vegetação não apresenta interesse significativo.

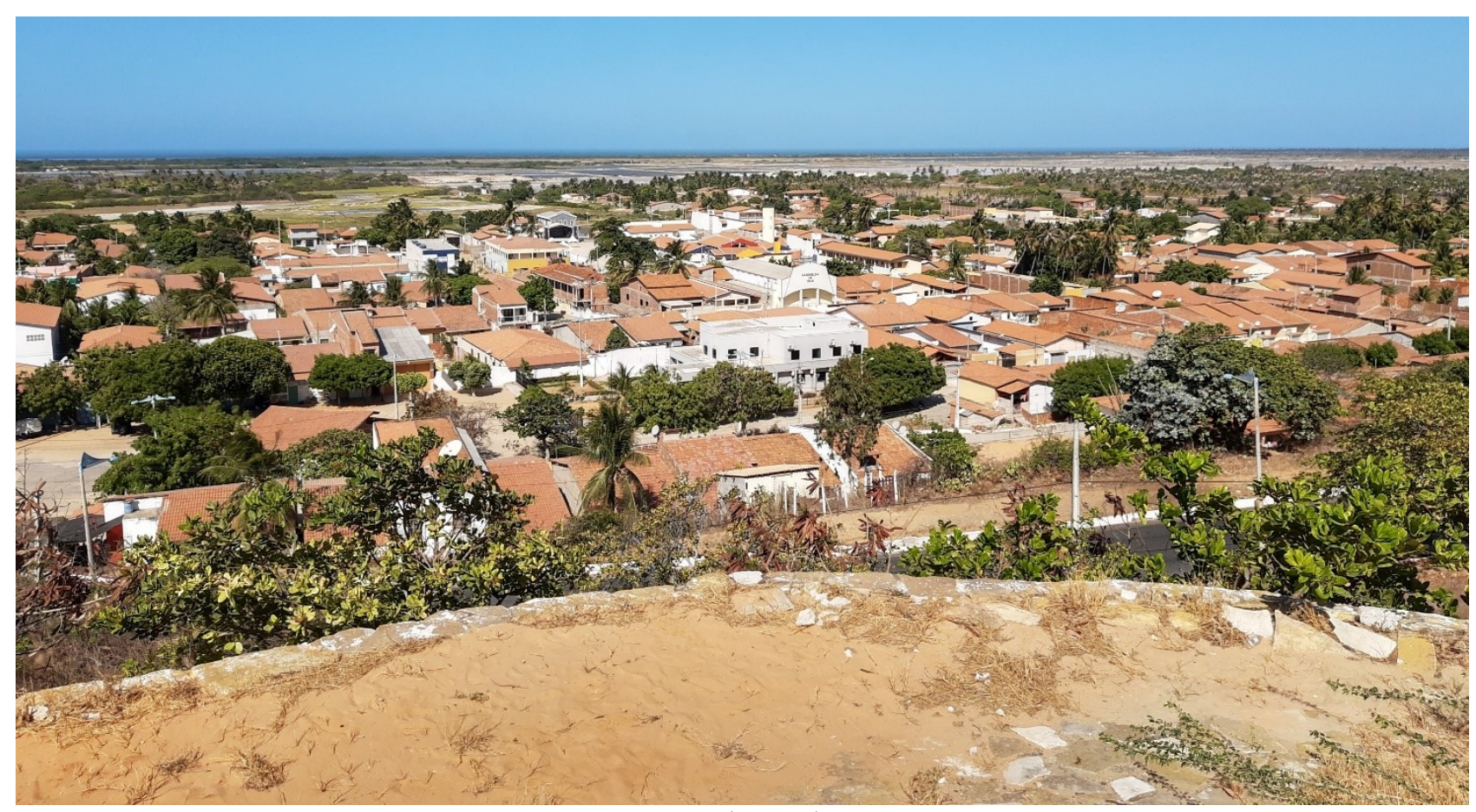

Figura 8 - Mirante do Icapuí.

Fonte: Acervo dos autores, 2020.

No valor paleogeográfico (A6) a pontuação máxima (valor 4) foi direcionado às praias de Ponta Grossa, Sítio Retirinho e Picos/Vila Nova, devido a serem locais com a presença de neotectônica, evidenciada por dobramentos e falhas ocorridos no período do Cenozoico, assim como destacou Souza (2003). O que também ocorreu nas Praias da Redonda/Peroba, mas nessas áreas há a ocorrência de interferência antrópica o que fez cair a pontuação para 3. A pontuação 3 foi atribuída as Praias da Redonda/Peroba, Requenguela e os Mirantes da Serra do Mar e do Icapuí, pois ambos os locais tem a presença de infraestrutura urbana que modificou o espaço, mas que são instrumentos ilustrativos para o ensino de modo geral. E por fim, a Praia de Manibu recebeu a pontuação 0, pois é sítio muito recente, que não tem uma história natural significativa como os demais mencionados. 


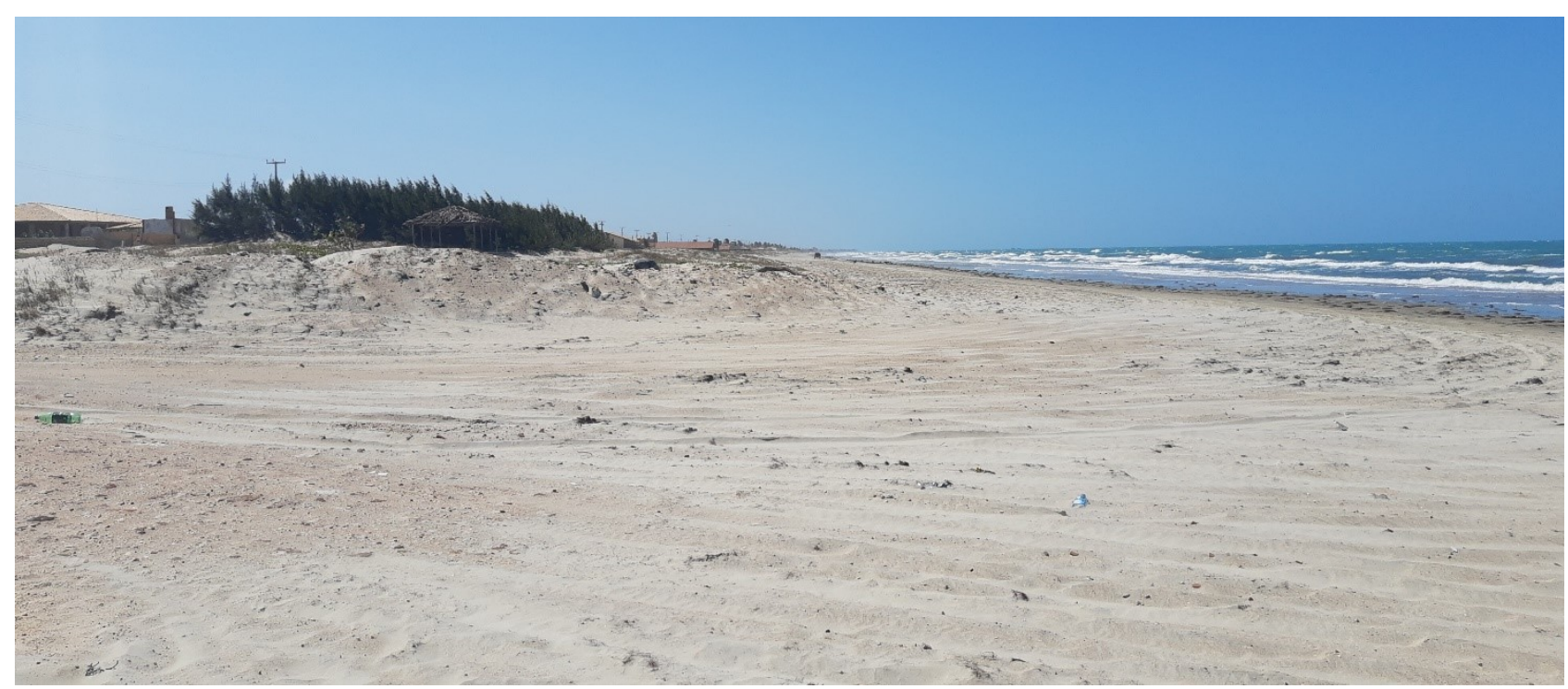

Figura 9 - Praia de Manibu.

Fonte: Acervo dos autores, 2020.

A relevância didática (A7) é o último parâmetro analisado do valor científico. Diante da importância que todos os sítios representam, ambos foram considerados como instrumentos passíveis de serem utilizados para fins didáticos, tanto para um público em geral como para todos os níveis de ensino, seja da educação básica ou do ensino superior (Valor 4).

Os valores dos parâmetros e total da categoria é vista na tabela 06, junto com as classes de avaliação, que considerou como geomorfossítios o Sítio Retirinho, as Praias de Ponta Grossa, Requenguela, Redonda/Peroba e Picos/Vila Nova por apresentarem alto valor científico com intervalo de 22-28, sendo considerados geomorfossítios por este valor. Na tabela 07 é possível observar os valores totais de todos os sítios em colunas para facilitar a visualização dos resultados.

Tabela 07: Valor Científico dos sítios de interesse geomorfológico.

\begin{tabular}{cccccccccc}
\hline \multicolumn{7}{c}{ VALOR CIENTÍfICO } \\
\hline SítIOS & A1 & A2 & A3 & A4 & A5 & A6 & A7 & TOTAL & CLASSES DE AVALIAÇÃO \\
Sítio Retirinho & 2 & 4 & 4 & 4 & 4 & 4 & 4 & $\mathbf{2 6}$ & ALTO \\
Praia de Ponta Grossa & 4 & 4 & 4 & 4 & 1 & 4 & 4 & $\mathbf{2 5}$ & ALTO \\
Praia de Requenguela & 2 & 4 & 4 & 4 & 4 & 3 & 4 & $\mathbf{2 5}$ & ALTO \\
Praias da Redonda/Peroba & 4 & 4 & 3 & 4 & 2 & 3 & 4 & $\mathbf{2 4}$ & ALTO \\
Praias de Picos/Vila Nova & 1 & 4 & 4 & 4 & 3 & 4 & 4 & $\mathbf{2 4}$ & ALTO \\
Praia de Manibu & 0 & 4 & 3 & 4 & 4 & 0 & 4 & $\mathbf{1 9}$ & MÉDIO \\
Mirante da Serra do Mar & 0 & 2 & 3 & 4 & 1 & 3 & 4 & $\mathbf{1 7}$ & MÉDIO \\
Mirante do Icapuí & 0 & 2 & 3 & 4 & 1 & 3 & 4 & $\mathbf{1 7}$ & MÉDIO \\
\hline
\end{tabular}

Legenda: A1 (Grau de conhecimento), A2 (Ecodinâmica dos meios), A3 (Representatividade de materiais e processos geomorfológicos), A4 (Diversidade de aspectos geomorfológicos - formas e processos), A5 (Interesse ecológico), A6 (Valor paleogeográfico) e A7 (Relevância Didática). Em destaque os locais que apresentam alto potencial.

Fonte: Elaborado pelos autores (2020). 


\subsection{Valor Estético (VEst)}

O primeiro parâmetro quantificado da categoria do valor estético é a raridade (B1) e apenas a Praia da Requenguela se enquadrou no valor máximo da avaliação (4), sendo considerado como um exemplo único na área, representado pelo delta de maré que forma um estuário e pelas condições geomorfológicas (baixa energia das ondas, corrente longitudinal quase nula e outros) que determinam o ecossistema de manguezal individual num contexto de mais de $200 \mathrm{~km}$ de linha de costa.

As Praias de Ponta Grossa e os Mirantes da Serra do Mar e do Icapuí obtiveram a pontuação 3, que expressa a existência de até 3 exemplares com características similares na área, dentro do mesmo contexto geomorfológico em um raio de $200 \mathrm{Km}$. As Praias da Redonda/Peroba, Picos/Vila Nova e Sítio Retirinho representam locais com existência de até cinco exemplares com características similares na área, dentro do mesmo contexto geomorfológico em um raio de $200 \mathrm{Km}$ (Valor 2). E a Praia de Manibu foi considerada como ocorrência comum na área da investigação (Valor 0).

A integridade (B2) dos sítios só apresentou valor máximo nas Praias de Picos/Vila Nova e Ponta Grossa (ainda não houve uma intensa exploração humana na área). O valor 3 que retrata sítio com alguma deterioração, mas com boas condições de visualização foi destinado para as Praias de Requenguela (a sociedade não modificou drasticamente o local), Manibu (alterações relacionadas com ocupação humana na costa) e o Mirante da Serra do Mar (como está sobre uma praça pública, apresenta pichações e também inserção de agricultura irrigada sobre os terrações vistos do mirante).

Apenas o Mirante do Icapuí obteve o valor 2, apresenta pichações e presença significativa das urbanizações. As Praias da Redonda/Peroba (ocupação humana na costa e forte erosão sobre a praia, com contenção para o avanço do nível do mar) e Sítio Retirinho (área que foi modificada pela abrasão marinha, recuando as falésias) foram quantificadas como 1, sendo considerados como sítios deteriorados, porém permite a visualização dos aspectos de interesse, sem possibilidade de ser recuperado.

O parâmetro da variedade de elementos da geodiversidade e/ou temáticas associadas (B3) apresentou valor máximo (4) para o Sítio Retirinho (oceanografia, estratigrafia, petrologia, hidrologia e geologia), as Praias de Ponta Grossa (hidrogeologia, petrologia, oceanografia, geologia, hidrologia, estratigrafia e outros), Redonda/Peroba (hidrologia, oceanografia, petrologia, estratigrafia, geologia e outros), Picos/Vila Nova (hidrologia, petrologia, estratigrafia, geologia, oceanografia e outros), Requenguela (hidrologia, oceanografia, hidrogeologia, hidrografia e outros) e o Mirante do Icapuí (hidrologia, oceanografia, geologia, hidrogeologia e outros). O Mirante da Serra do Mar recebeu o valor 3 na avaliação, pois só apresentou três temáticas associadas (oceanografia, hidrologia e geologia) e para Praia de Manibu estabeleceu o valor 2 (hidrologia e oceanografia). 
No item da qualidade Visual (B4) apenas a Praia de Ponta Grossa obteve valor máximo na avaliação (4), sítio dotado de espetacularidade estética e inserido em local aprazível, dotado de apelo cênico, com verticalidade de 80 metros, devido à presença de dunas sobre a falésia ativa, relevo montanhoso e contraste de 11 cores (Figura 10). O valor 3 foi destinado apenas para as Praias de Picos/Vila Nova considerado com verticalidade maior que 50 metros e contraste de oito cores.

\section{PRAIA DE PONTA GROSSA}

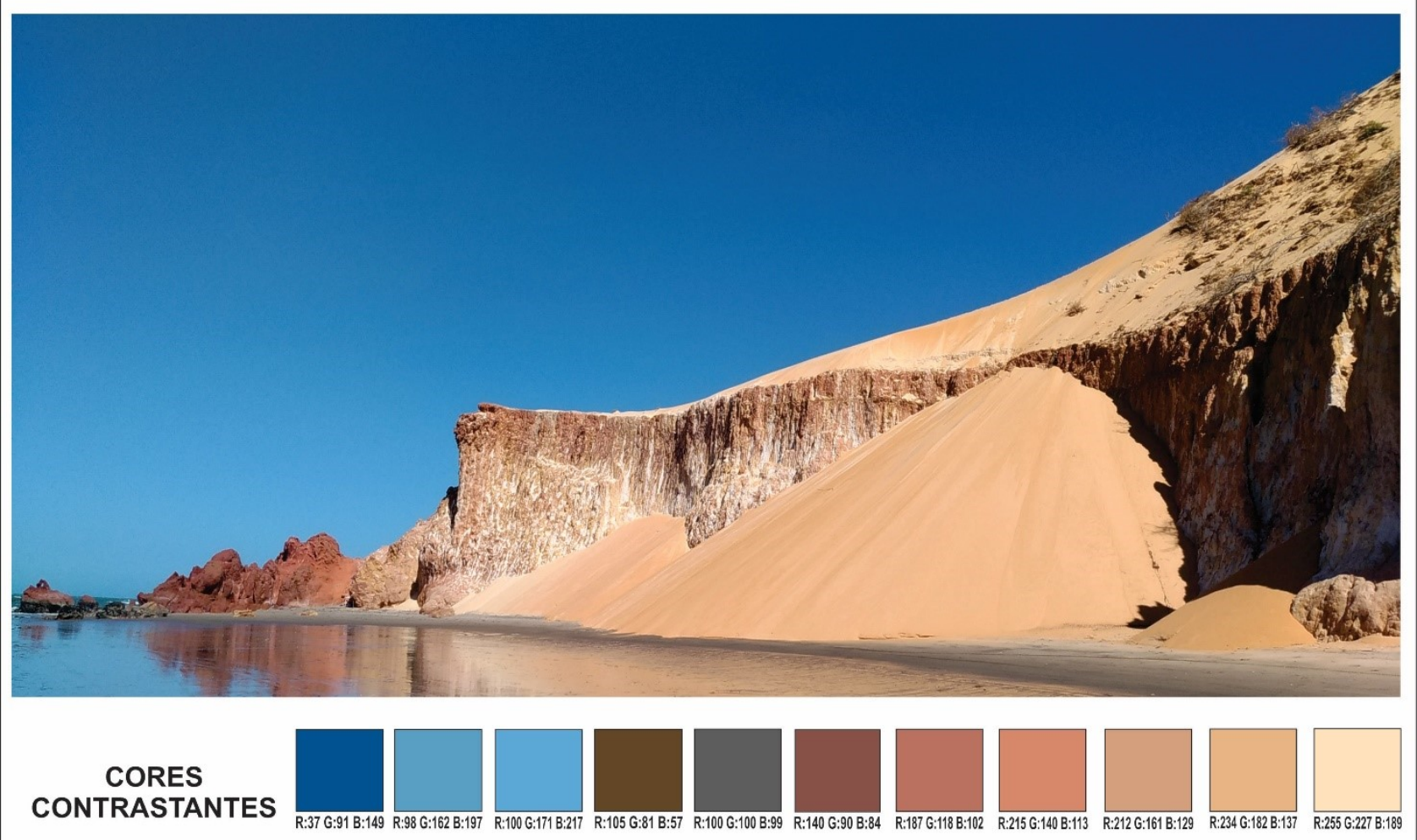

Figura 10 - Exemplo do contraste de cores, na Praia de Ponta Grossa.

Fonte: Elaborado pelos autores, 2020.

Com o valor 2 estão as Praias da Redonda/Peroba (contraste superior a nove cores e verticalidade inferior aos $50 \mathrm{~m}$ ), Requenguela (cinco cores contrastantes e relevo plano), os Mirantes da Serra do Mar (9 cores contrastantes e verticalidade inferior aos $50 \mathrm{~m}$ ), do Icapuí (7 cores contrastantes e verticalidade inferior aos $50 \mathrm{~m}$ ) e Sítio Retirinho (quatro cores e verticalidade inferior a 50 metros). A Praia de Manibu corresponde ao valor 1, pois é inserido em local aprazível ou dotado de algum elemento com apelo estético (3 cores contrastantes e relevo plano).

Por fim, no parâmetro de condições de observação (B5) o valor máximo (4) foi para a Praia de Ponta Grossa (visualização sobre a falésia e dunas) e nos Mirantes da Serra do Mar e da Gruta de Icapuí (Mirantes), pois apresentam boas condições, com paisagem e verticalidade. Os demais sítios se enquadraram no valor 3 , com boas condições, mas apenas observável a partir da base. 
A partir da proposta da pesquisa, as Praias de Ponta Grossa, Requenguela e Picos/Vila Nova, foram também considerados geomorfossítios pelo alto valor estético (entre 16 a 20). Segue o valor total de cada sítio para a categoria do valor estético, na tabela 08 .

Tabela 08: Valor Estético dos sítios de interesse geomorfológico.

\begin{tabular}{|c|c|c|c|c|c|c|c|}
\hline \multicolumn{8}{|c|}{ VALOR ESTÉTICO } \\
\hline SÍTIOS & B1 & $\mathbf{B 2}$ & B3 & B4 & B5 & TOTAL & CLASSES DE AVALIAÇÃO \\
\hline Praia de Ponta Grossa & 3 & 4 & 4 & 4 & 4 & 19 & ALTO \\
\hline Praia de Requenguela & 4 & 3 & 4 & 2 & 3 & 16 & ALTO \\
\hline Praias de Picos/Vila Nova & 2 & 4 & 4 & 3 & 3 & 16 & ALTO \\
\hline Mirante da Serra do Mar & 3 & 3 & 3 & 2 & 4 & 15 & MÉDIO \\
\hline Mirante do Icapuí & 3 & 2 & 4 & 2 & 4 & 15 & MÉDIO \\
\hline Sítio Retirinho & 2 & 1 & 4 & 2 & 3 & 12 & MÉDIO \\
\hline Praias da Redonda/Peroba & 2 & 1 & 4 & 2 & 3 & 12 & MÉDIO \\
\hline Praia de Manibu & 0 & 3 & 2 & 1 & 3 & 9 & BAIXO \\
\hline
\end{tabular}

Legenda: B1 (Raridade), B2 (Integridade), B3 (Variedade de elementos da geodiversidade e/ou temáticas associadas), B4 (Qualidade visual) e B5 (Condições de observação). Em destaque os locais que apresentam alto potencial.

Fonte: Elaborada pelos autores (2020).

\subsection{Valor Turístico (VTur)}

O primeiro item avaliado no valor turístico é a acessibilidade $(\mathrm{C} 1)$ e cinco locais obtiveram a pontuação máxima (4) que foram: as Praias de Picos/Vila Nova (estradas asfaltadas), Requenguela (estradas pavimentadas), Manibu (estradas asfaltadas), Mirante da Serra do Mar (estradas asfaltadas), Mirante do Icapuí (estradas asfaltadas), devido ser acessível através de estradas principais (federais, estaduais ou municipais). As Praias de Ponta Grossa e Redonda/Peroba foram avaliadas com 3, pois são acessíveis por estradas pavimentadas ou com trilhas com menos de $2 \mathrm{Km}$ de extensão e o Sítio Retirinho é um local com acesso por estradas não pavimentadas (Valor 2).

Na presença de infraestrutura a Praia de Ponta Grossa (restaurantes, hospedagem, banheiros e guias turísticos), Praias da Redonda/Peroba (restaurantes, hospedagem, banheiros e guias turísticos), Requenguela (restaurantes, hospedagem, banheiros e guias turísticos) e Praia de Manibu (restaurantes, hospedagem, banheiros e guias turísticos), obtiveram a pontuação mais elevada da categoria (4), pois há a existência de quatro elementos que servem de apoio ao visitante. A Praia de Picos (restaurantes, pousadas e banheiros) expõe o valor 3, pois só inclui três elementos. Os Mirantes da Serra do Mar (restaurantes e banheiros) e do Icapuí (restaurantes e banheiros) e o Sítio Retirinho (hospedagem e guias turísticos) estão relacionados apenas com dois aspectos, pois se encontram em áreas residenciais (Valor 2).

$\mathrm{Na}$ existência de utilização em curso (C3) nenhum local obteve a pontuação máxima, as Praias de Ponta Grossa, da Redonda/Peroba, Requenguela, Manibu e Sítio Retirinho resultaram no valor 3, por possuírem alta taxa de visitação, porém não existem mecanismos de controle de visitantes e há hospedagens hospedagens. No valor 2, foi enquadrada a Praia de Picos/Vila Nova, com média 
taxa de visitação e presença de hospedagens, e por fim, os Mirantes da Serra do Mar e do Icapuí que resultaram em 1, em razão de apresentar alguma taxa de visitação, ainda incipiente.

Com relação a questão do cenário (C4), as Praia de Ponta Grossa e Redonda/Peroba resultaram no valor 3, pois aparecem ocasionalmente em campanhas nacionais. $\mathrm{O}$ valor 2 enquadrou os demais sítios: Praias de Picos/Vila Nova, Requenguela, Sítio Retirinho, os Mirantes da Serra do Mar e do Icapuí e a Praia de Manibu, devido serem frequentes apenas em campanhas locais (referente ao turismo de sol e praia).

Por fim, na categoria turística (C5), o valor máximo (4) foi obtido por três sítios, por apresentar quatro ou mais categorias turísticas, sendo eles: as praias de Ponta Grossa (aventura, ecoturismo, sol e praia, estudos), Requenguela (ecoturismo, sol e praia, geoturismo e estudos) e o Mirante do Icapuí (cultural, sol e praia, religioso e estudos). O valor 3 foi destinado as Praias de Picos/Vila Nova (sol e praia, geoturismo e estudos) e Redonda/Peroba (sol e praia, geoturismo e estudos). E o valor 2 enquadrou o Mirante da Serra do Mar (sol e praia e estudos), Sítio Retirinho (sol e praia e estudos) e Praia de Manibu (sol e praia e estudos).

Os valores totais da categoria são vistos na tabela 09, juntos com as classes de avaliação, que indicaram que apenas as praias de Ponta Grossa, Requenguela e Redonda/Peroba apresentaram alto valor turístico, oferecendo no geral boas estrutura aos visitantes.

Tabela 09: Valor total dos locais de interesse geomorfológico.

\begin{tabular}{|c|c|c|c|c|c|c|c|}
\hline \multicolumn{8}{|c|}{ VALOR TURÍSTICO } \\
\hline Praia de Requenguela & 4 & 4 & 3 & 2 & 4 & 17 & ALTO \\
\hline Praias da Redonda/Peroba & 3 & 4 & 3 & 3 & 3 & 16 & ALTO \\
\hline Praias de Picos/Vila Nova & 4 & 3 & 2 & 2 & 3 & 14 & MÉDIO \\
\hline Mirante do Icapuí & 4 & 2 & 1 & 2 & 4 & 13 & MÉDIO \\
\hline Mirante da Serra do Mar & 4 & 2 & 1 & 2 & 2 & 11 & MÉDIO \\
\hline
\end{tabular}

Legenda: B1 (Raridade), B2 (Integridade), B3 (Variedade de elementos da geodiversidade e/ou temáticas associadas), B4 (Qualidade visual) e B5 (Condições de observação). Em destaque os locais que apresentam alto potencial.

\subsection{Valor de Uso e Gestão (VUG)}

Na categoria de uso e gestão, foi quantificado inicialmente o parâmetro de uso Limitado (D1) e o valor máximo (4) foi distribuído para seis locais, sendo eles: Sítio Retirinho, Praias da Redonda/Peroba, Requenguela, Manibu e os Mirantes da Serra do Mar e do Icapuí, pois não apresentam limitações e as observações podem ser feitas na base, o que não compromete a segurança de crianças, por exemplo. As Praias de Picos/Vila Nova foi valorada com 2 pontos, pois é preciso 
superar algumas limitações físicas (caminhada e subida em blocos). E por fim, a Praia de Ponta Grossa recebeu o valor 1, pois necessita de uma condição física mais satisfatória, devido ao fato de haver trilhas e subidas em dunas.

Na relevância cultural (D2) só apresentou valor elevado (4) o Mirante do Icapuí, pois a área possui uma estreita relação com elementos culturais (paisagem cultural e religiosa), com a presença de uma gruta artificial para oração (Figura 11).

As Praias de Ponta Grossa (jangadas), Redonda/Peroba (jangadas e pesca artesanal), Picos/Vila Nova (jangadas), Requenguela (pesca artesanal e banco de algas) receberam o valor 2, por serem uma contribuição acessória para suas áreas. O Sítio Retirinho, Praia de Manibu e o Mirante da Serra do Mar são sítios que não apresentaram nenhuma relação cultural (Valor 0).

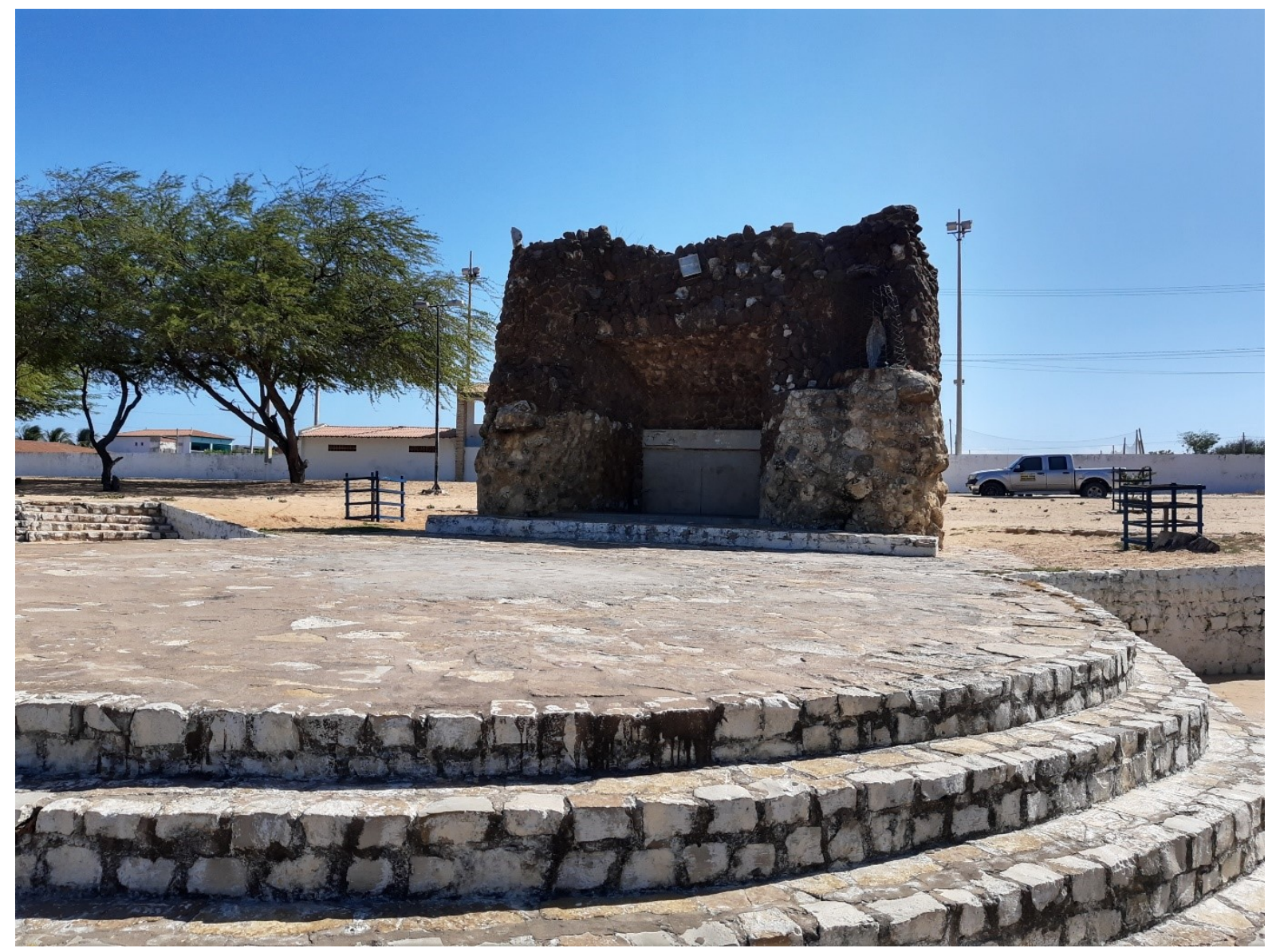

Figura 11 - Gruta artificial no Mirante do Icapuí.

A parte inferior da gruta (tons claros) foi construída com calcário da Formação Jandaíra, já a parte superior (tons escuros) foi construída com fragmentos de laterita das falésias do Grupo Barreiras.

Fonte: Acervo dos autores, 2020.

A relevância econômica (D3) é um parâmetro que avalia as atividades econômicas, exceto o turismo, e é pontuada de forma inversamente proporcional. O Sítio Retirinho, as Praias de Picos/Vila Nova e Manibu representam ausência de qualquer potencial econômico (Valor 4). As Praias da Redonda/Peroba, possui potencial de pesca, porém ainda é incipiente (Valor 3). A Praia de Ponta 
Grossa possui potencial de pesca, a exploração é incipiente, mas regularizada (Valor 2). Por fim, a praia de Requenguela (pesca artesanal) e os Mirantes da Serra do Mar (agricultura irrigada) e do Icapuí (salinas), tem viabilidade econômica com atividade exploratória estabelecida e organizada (Valor 0).

O nível de proteção oficial (D4) é máximo (valor 4) para as Praias Ponta Grossa (Área Preservação Permanente (APP) - praia, dunas e declividade; Área de Proteção Ambiental (APA) de Ponta Grossa), Redonda/Peroba (APP - praias, dunas; APA de Ponta Grossa), Picos/Vila Nova (APP - praia e declividade), Requenguela (APP - praia; APA da Barra Grande), Manibu (APP - praia) e Sítio Retirinho (APP - praia e declividade). Os Mirantes da Serra do Mar e do Icapuí não estão enquadrados em nenhuma área de preservação ambiental (Valor 0).

A vulnerabilidade associada ao uso antrópico (D5) teve valor 3 apenas na Praia de Ponta Grossa e Sítio Retirinho, que poderão sofrer processos erosivos desencadeados pela atividade antrópica, mediante uso ou visitação, podendo ser utilizado de acordo com um plano de manejo. $\mathrm{O}$ mesmo ocorre para os Mirantes da Serra do Mar (ocupação humana no entorno) e na Gruta do Icapuí (ocupação humana no entorno). A Praia de Requenguela (ocupação humana em costa) obteve a pontuação 2 , sendo sujeita a descaracterização pelo uso, que pode ser utilizado mediante a implementação de infraestrutura em palafita para minimizar os impactos. As Praias da Redonda/Peroba (ocupação humana em costa e contenção de erosão), Picos/Vila Nova (ocupação humana em costa) e Manibu (ocupação humana em costa) foram pontuados com 1, pois a implementação de infraestrutura rígida pode tornar o ambiente vulnerável.

No item de densidade populacional ou população do núcleo urbano mais próximo (D6), todos os locais resultaram no mesmo valor (1), em razão de que os sítios são localizados no município com menos de $100 \mathrm{hab} / \mathrm{Km}^{2}$ ou 5.000 a 10.000 habitantes em um raio de $25 \mathrm{Km}$. O último item, ou seja, as condições socioeconômicas dos núcleos urbanos mais próximos (D7) também foi valorado com o valor máximo para todos os locais (1), pois Icapuí apresenta um IDH (Índice de Desenvolvimento Humano) inferior ao IDH médio da Região Imediata.

Assim, o valor total dos sítios é observado na tabela 10, assim como as classes de avaliação, que apontaram os sítios que foram considerados com alto, médio e baixo potencial de uso e gestão.

Tabela 10: Valor de uso e gestão total dos locais de interesse geomorfológico.

\begin{tabular}{ccccccccccc}
\hline & \multicolumn{10}{c}{ VALOR DE USO E GESTÃo } \\
\hline SítIOS & D1 & D2 & D3 & D4 & D5 & D6 & C7 & TOTAL & CLASSES DE AVALIAÇÃo \\
Sítio Retirinho & 4 & 0 & 4 & 4 & 3 & 1 & 1 & $\mathbf{1 7}$ & MÉDIO \\
Praias da Redonda/Peroba & 4 & 3 & 3 & 4 & 1 & 1 & 1 & $\mathbf{1 7}$ & MÉDIO \\
Praias de Picos/Vila Nova & 2 & 3 & 4 & 4 & 1 & 1 & 1 & $\mathbf{1 6}$ & MÉDIO \\
Praia de Ponta Grossa & 1 & 3 & 2 & 4 & 3 & 1 & 1 & $\mathbf{1 5}$ & MÉDIO
\end{tabular}




\begin{tabular}{|c|c|c|c|c|c|c|c|c|c|}
\hline Praia de Requenguela & 4 & 3 & 0 & 4 & 2 & 1 & 1 & 15 & MÉDIO \\
\hline Praia de Manibu & 4 & 0 & 4 & 4 & 1 & 1 & 1 & 15 & MÉDIO \\
\hline Mirante do Icapuí & 4 & 4 & 0 & 0 & 3 & 1 & 1 & 13 & BAIXO \\
\hline Mirante da Serra do Mar & 4 & 0 & 0 & 0 & 3 & 1 & 1 & 9 & BAIXO \\
\hline
\end{tabular}

Legenda: D1 (Uso limitado), D2 (Relevância cultural), D3 (Relevância econômica), D4 (Nível de proteção oficial), D5 (Vulnerabilidade associada ao uso antrópico), D6 (Densidade populacional ou população do núcleo mais próximo) e D7 (Condições socioeconômicas dos núcleos urbanos mais próximos).

Fonte: Elaborada pelos autores, 2020.

\subsection{Valor Geomorfológico (VGm), de Gestão (VGt), Valor Total (VT) e Ranking Final (RK)}

Com a realização de todos os cálculos das categorias anteriores, é possível traçar o valor geomorfológico e de gestão através de uma média aritmética, respectivamente. Assim, o primeiro está relacionado com a média aritmética entre os valores científico e estético. Esse valor representa as principais características geomorfológicas encontradas na área invstigada. $\mathrm{O}$ segundo indicador refere-se ao modo como é gerido e condições de apoio para os turistas, sendo realizado através de uma média aritmética entre os valores turístico e de uso e gestão. E por fim, o valor total é resultante da soma entre os valores geomorfológico e de gestão, podemos observar na tabela 11.

Tabela 11: Valores geomorfológico, de gestão e o total

\begin{tabular}{cccccccc}
\hline Sítios & VCi & VEst & VGm & VTur & VUG & VGt & VT \\
\hline Praia de Ponta Grossa & 25 & 19 & 22 & 17 & 15 & 16 & 38 \\
Sítio Retirinho & 26 & 12 & 19 & 11 & 17 & 14 & 33 \\
Praias de Picos e Vila Nova & 24 & 16 & 20 & 14 & 16 & 15 & 35 \\
Praia de Requenguela & 25 & 16 & 20,5 & 17 & 15 & 16 & 36,5 \\
Mirante da Serra do Mar & 17 & 15 & 16 & 11 & 9 & 10 & 26 \\
Mirante do Icapuí & 17 & 15 & 16 & 13 & 13 & 13 & 29 \\
Praias da Redonda e Peroba & 24 & 12 & 18 & 16 & 17 & 16,5 & 34,5 \\
Praia de Manibu & 19 & 9 & 14 & 15 & 15 & 15 & 29 \\
\hline
\end{tabular}

Legenda: VCi (Valor Científico), VEst (Valor Estético), VGm (Valor Geomorfológico), VTur (Valor Turístico), VUG (Valor de Uso e Gestão), VGt (Valor de Gestão) e VT (Valor Total).

Fonte: Elaborada pela autora, 2020.

O Ranking Final (RK) evidenciou a somatória de todas as posições de cada sítio para cada categoria e indicador, com a finalidade de considerar apenas aqueles que obtiveram o menor número de colocações, pois retrata que esses locais apresentam uma maior representatividade. Ficou notório que os geomorfossítios considerados para a zona costeira de Icapuí/CE pelos valores científico e estético, estão também posicionados nas cinco primeiras colocações do RK, que confirma que os sítios são locais prioritários para geoconservação na área.

Na tabela 12 podemos obsrevar o Ranking Final (RK). 
Tabela 12: Ranking Final dos locais de interesse geomorfológico.

\begin{tabular}{|c|c|c|c|c|c|c|c|c|}
\hline Posição & Vei & Vest & VGm & VTur & VUG & VGt & VT & RF \\
\hline $1^{\circ}$ & A (26) & B (19) & B (22) & B (17) & A (17) & $\mathrm{C}(16,5)$ & B (38) & B (12) \\
\hline $2^{\circ}$ & B (25) & D (16) & $\mathrm{E}(20,5)$ & E (17) & C (17) & B (16) & $\mathrm{E}(36,5)$ & E (20) \\
\hline $3^{\circ}$ & E (25) & E (16) & $\mathrm{D}(20)$ & C (16) & D (16) & E (16) & D (35) & D (24) \\
\hline $4^{\circ}$ & D (24) & F (15) & A (19) & H (15) & B (15) & $\mathrm{D}(15)$ & $\mathrm{C}(34,5)$ & C (27) \\
\hline $5^{\circ}$ & C (24) & G (15) & C (18) & D (14) & E (15) & $\mathrm{H}(15)$ & A (33) & A (30) \\
\hline $6^{\circ}$ & H (19) & A (12) & F (16) & G (13) & $\mathrm{H}(15)$ & A (14) & G (29) & H (44) \\
\hline $7^{\circ}$ & $\mathrm{F}(17)$ & C (12) & G (16) & A (11) & G (13) & G (13) & H (29) & G (46) \\
\hline $8^{\circ}$ & $\mathrm{G}(17)$ & $\mathrm{H}(9)$ & H (14) & $\mathrm{F}(11)$ & F (9) & $\mathrm{F}(10)$ & F (26) & F (49) \\
\hline
\end{tabular}

Legenda: A (Sítio Retirinho), B (Praia de Ponta Grossa), C (Praias da Redonda/Peroba), D (Praias de Picos/Vila Nova), E (Praia de Requenguela), F (Mirante da Serra do Mar), G (Mirante do Icapuí) e H (Praia de Manibu).

Fonte: Elaborada pela autora, 2020.

O mapeamento realizado para avaliação quantitativa foi baseado no trabalho de Reynard et al., (2016), contendo os sítios considerados como geomorfossítios, pelos valores científico e estético, bem como os que apresentaram alto valor turístico (sítios da geomorfodiversidade), na planície costeira de Icapuí/CE. O valor de uso e gestão (VUG) não foi abordado, pois nenhum sítio apresentou um valor alto na categoria, na figura 12 podemos observar o mapeamento.

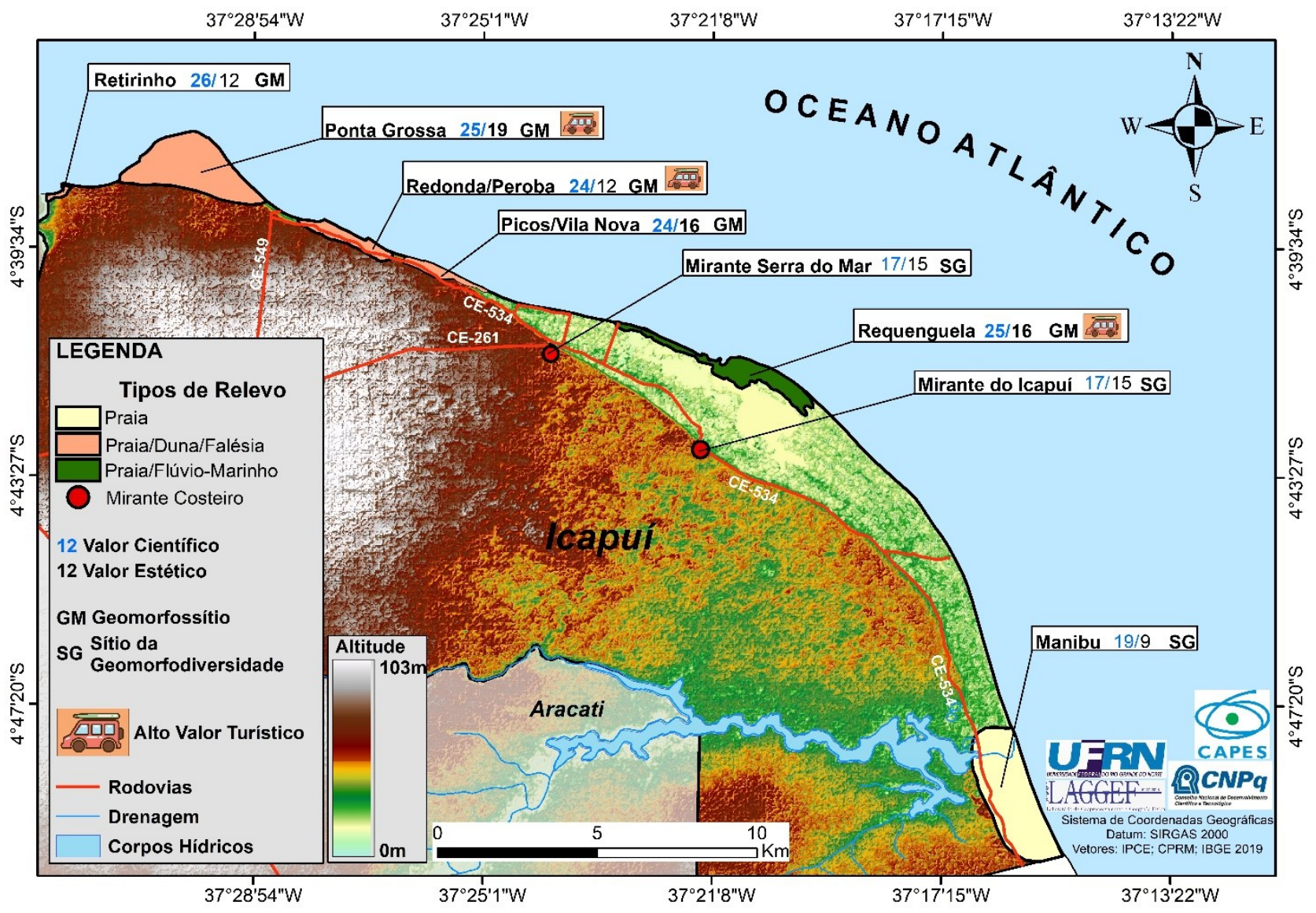

Figura 12 - Mapa síntese da planície costeira de Icapuí/CE.

Fonte: Elaborado pelos autores, 2020. 


\subsection{Definição de Geomorfossítios e Sítios da Geomorfodiversidade}

Este trabalho considerou que geomorfossítios são os que apresentam alto valor científico (valores entre 22-28) e/ou estético (valores entre 16 a 20), dessa forma foram considerados: as Praias de Ponta Grossa (científico e estético), Redonda/Peroba (científico), Picos/Vila Nova (científico e estético), Requenguela (científico e estético) e Sítio Retirinho (científico). Os sítios que apresentaram valores médios no científico, estético, turístico e de uso e gestão, assim como alto nos dois últimos mencionados, foram considerados como sítios da geomorfodiversidade. Enquadra-se nessa categoria os Mirantes da Serra do Mar e do Icapuí e a Praia de Manibu.

Portanto, o patrimônio geomorfológico da zona costeira de Icapuí condiz com cinco geomorfossítios e três locais de interesse geomorfológico.

A hipótese de que poderiam haver locais com alto valor estético sem, no entanto, ter alto valor científico não pode ser confirmada em Icapuí, pois os três geomorfossítios de alto valor estético também tiveram alto valor científico. Contudo com a replicação do método proposto neste artigo em outras áreas de estudo esta hipótese poderá ser confirmada.

\section{CONSIDERAÇÕES FINAIS}

Os geomorfossítios que exibiram alto valor estético na proposta, também apresentou alto valor científico, o que não comprovou a hipótese da pesquisa, porém, a replicação dos métodos em outras áreas, podem obter um resultado contrário, tendo o mesmo peso na avaliação. $\mathrm{O}$ trabalho desenvolvido serve como um novo instrumento para a geomorfodiversidade, avaliando características mais direcionadas a geomorfologia, contudo, entende-se que o método desenvolvido no trabalho pode ser adaptado para estudos em outros geopatrimônios.

Além disso, a zona costeira de Icapuí apresentou uma diversidade de elementos geomorfológicos (formas e processos) que se mostraram realçar a geomorfodiversidade na área de estudo, que consequentemente, despertam o interesse turístico para a sociedade.

Diante disso, conclui-se que o método é eficaz e promissor para ser aplicado em outros sítios de estudos inerentes ao geopatrimônio, enfatizando o geomorfopatrimônio, utilizando de parâmetros claros e objetivos para diminuir a subjetividade antes discutida em outros estudos. O município de Icapuí também ganha destaque ao lado do método de avaliação dos sítios, pois é no mesmo que encontramos tamanha potencialidades para estudos e suas importâncias para a ciência. 


\section{AGRADECIMENTOS}

Os autores agradecem à Coordenação para Aperfeiçoamento de Pessoal de Ensino Superior - CAPES pela bolsa de mestrado da primeira autora e ao Conselho Nacional de Desenvolvimento Científico e Tecnológico - CNPq pela bolsa de produtividade em pesquisa do segundo autor.

\section{REFERÊNCIAS}

BRASIL. Plano Nacional de Turismo 2018-2022: mais emprego e renda para o Brasil. Disponível em: < http://www.turismo.gov.br/images/pdf/PNT_2018-2022.pdf.>. Acesso em: 20 fev. 2020.

BRILHA, J. Inventory and Quantitative assessment of geosites and geodiversity sites: a review. Geoheritage, n. 8, p. 119-134, 2016.

CLAUDINO-SALES, V. Morfopatrimonio, morfodiversidade: pela afirmacao do patrimonio geomorfologico strict sensu. Revista da Casa da Geografia de Sobral (RCGS), v. 20, p. 3-12, 2018.

CORATZA, P.; GIUSTI, C. Methodological proposal for the assessment of the scientific quality of geomorphosites. Italian Journal of Quaternary Sciences, v. 1, n. 18, p. 307-313, 2005.

DINIZ, M. T. M.; ARAÚJO, I. G. D.; TERTO, M. L, O.; SILVA, S. D. R. Nem Paisagem, Nem Geossistema, Geoforma como Categoria Fundamental da Geomorfodiversidade. William Morris Davis - Revista de Geomorfologia, v. 1, n. 1, p. 251-263, 2020.

DUPONT, L.; ANTROP, M.; VAN EETVELDE, V. Eye-tracking Analysis in Landscape Perception Research: Influence of Photograph Properties and Landscape Characteristics. Landscape Research, v. 39, p. 01-16, 2013.

GRAY, M. Geodiversity: valuing and conserving abiotic nature. 2. ed. Chichester: John Wiley \& Sons, 2013. 495p.

ICAPUÍ. Lei Municipal n 262 de 08 de abril de 1998.Dispõe sobre a criação da Área de Proteção Ambiental - APA da Praia de Ponta Grossa e adota outras providências. Diário Oficial [da] República Federativa do Brasil, Prefeitura Municipal de Icapuí, CE, 08 abr. 1998.

ICAPUÍ. Lei Municipal n 298 de 12 de maio de 2000. Institui a Área de Proteção Ambiental da Barra Grande. Diário Oficial [da] República Federativa do Brasil, Prefeitura Municipal de Icapuí, CE, 12 mai. 2000.

ICAPUÍ. Lei Municipal n 634, 25 de fevereiro de 2014. Dispõe sobre alteração da Lei 298/2000, de 12 de maio de 2000. Cria a Área de Proteção Ambiental - APA do manguezal da barra grande, e dá outras providências. Diário Oficial [da] República Federativa do Brasil, Prefeitura Municipal de Icapuí, CE, 25 fev. 2014.

IBGE - INSTITUTO BRASILEIRO DE GEOGRAFIA E ESTATÍSTICA. Divisões Regionais do Brasil. 2017. Disponível em: <http://www.ibge.gov.br/organizacao-do-territorio/divisaoregional/15778-divisoes-regionais-do-brasil/>. Acesso em: 3 nov. 2019.

IPECE. Perfil Básico dos Municípios. Icapuí-CE, 2017. 
LOPES, L. S. O. Estudo Metodológico de Avaliação do Patrimônio Geomorfológico: aplicação no litoral do estado do Piauí. 2017. 216 f. Tese. (Doutorado em Geografia) - Universidade Federal de Pernambuco, Recife, 2017.

MEIREleS, A. J. A.; SIlvA, J. A.; SOUZA, W. F. Área de Proteção Ambiental (APA) da Barra Grande em Icapuí-CE: caminhos para a sustentabilidade. Conexões Ciência e Tecnologia, v. 11, n. 5, p. 90-100, 2017.

OLIVEIRA, P. C. A. Avaliação do patrimônio geomorfológico potencial dos municípios de Coromandel e Vazante, MG. Uberlândia, 2015. 176 f. Tese (Doutorado em Ciências Humanas) Universidade Federal de Uberlândia, Uberlândia, 2015.

PANIZZA, M., PIACENTE, S. Geomorphological assets evaluation, Zeitschr. Zeitschr Zeitschrift für Geomorphologie (ZfG), p. 13-18, 1993.

PANIZZA, M. Geomorphosites: concepts, methods and examples of geomorphological survey. Chinese Science Bulletin, v. 46, p. 1-6, 2001.

PANIZZA, M. The Geomorphodiversity of the Dolomites (Italy): A key of geoheritage Assessment. Geoheritage, Berlim, v. 1, n. 1 p. 33-42, 2009.

PEREIRA, P. J. S. Patrimônio geomorfológico: conceptualização, avaliação e divulgação. Aplicação ao Parque Natural de Montesinho. 2006. 370 f. Tese (Doutorado em Geociências) - Escola de Ciência, Universidade do Minho, Braga, 2006.

PEREIRA, R. G. F. de A. Geoconservação e desenvolvimento sustentável na Chapada Diamantina (Bahia-Brasil). 2010. 318 f. Tese (Doutorado em Geologia) - Universidade do Minho, Braga, 2010.

PEREIRA, L. S.; NOGUEIRA, H. Avaliação quantitativa do valor geoturístico do geopatrimónio caso do Litoral Sul Paraibano, Brasil. Cadernos de Geografia, n. 34, p. 55- 65, 2015.

REYNARD E.; CORATZA P. Geomorphosites and geodiversity: a new domain of research. Geographica Helvetica, n. 62, p. 138-139, 2007.

REYNARD, E. Fiche d'inventaire des géomorphosites. Université de Lausanne. Institute Geographie, rapport non-publié, 2006. Disponível em: $<$ http://www.unil.ch/igul/page17893.html>. Acesso em: 25 fev. 2020.

REYNARD, E.; PERRET, A.; BUSSARD, J.; GRANGIER, L.; MARTIN, S. Integrated Approach for the Inventory and Management of Geomorphological Heritage at the Regional Scale. Geoheritage, n. 8, p. 43-60, 2016.

REYNARD, E; FONTANA, G; KOZLIK, L; SCAPOZZA, C. A method for assessing scientific and additional values of geomorphosites. Geographica Helvetica, n. 62, p. 148-158, 2007.

REYNARD, E.; PANIZZA, M. Géomorphosites: définition, évaluation et cártographie: une introduction. Géomorphologie: relief, processus, environment, Paris, n. 3, p. 177-180, 2005.

SOUSA, D. C. Litoestratigrafia e deformação Cenozóica na região de Icapuí, Ceará, e implicações para a estruturação de campos de petróleo na borda ocidental da Bacia Potiguar 
(NE do Brasil). 2003. 192 f. Tese (Doutorado em Geodinâmica) - Universidade Federal do Rio Grande do Norte, Natal, 2003.

TRICART, J. Ecodinâmica. Rio de Janeiro: IBGE/SUPREN, 1977. 97p.

Trabalho enviado em 15/12/2020

Trabalho aceito em $01 / 03 / 21$ 